\title{
LA EDUCACIÓN \\ DESDE LA PERSPECTIVA \\ DE LA ESCUELA AUSTRIACA DE ECONOMÍA
}

\author{
FERNANDO NOGALES LOZANO*
}

\begin{abstract}
Resumen: La actual Planificación Central de la Educación no es solamente consecuencia del intenso activismo político de las sociales democracias europeas (muy en concreto de la española), también es consecuencia de la ausencia de una oposición ideológica clara por parte del liberalismo sociopolítico en general. Por tanto, reencontrar y en su caso redefinir las bases teóricas de la libertad de enseñanza, como es el caso de la Escuela Austriaca de Economía, para de-construir el actual modelo socialdemócrata de Planificación Central de la Educación, es hoy una exigencia. Dos son las razones fundamentales: la primera, por lo que significa de mejora para la plena libertad de los mercados privados de enseñanza, más ágiles, menos costosos y más eficaces para coordinar mejor las preferencias individuales de aprendizaje con las necesidades de los mercados. La segunda, por la eticidad que significa defender un sistema educativo basado en los principios liberales, de ausencia de coacción educativa estatista.
\end{abstract}

Palabras clave: Educación y Liberalismo, educación y Socialismo, bases evolucionistas y anarcocapitalistas de la Escuela Austriaca para una educación en libertad.

Clasificación JEL: 120, 121, 128.

Abstract: The current Central Planning of the Education is not only a consequence of intense political activism of the European social democracies (specifically in Spain), moreover is consequence of the absence of a clear ideological opposition by the socio-political liberalism. Therefore, the Austrian School of Economics has nowadays an obligation, rediscover and

* Máster en Economía de la Escuela Austriaca, Universidad Rey Juan Carlos (Madrid).

Procesos de Mercado: Revista Europea de Economía Política Vol. IX, n. ${ }^{-}$1, Primavera 2012, pp. 155 a 210 
redefine the theoretical basis of freedom of education to deconstruct the current social democratic model of Central Planning of Education. There are two essential reasons: the first one, because it means a improvement for the full freedom of the private education market, more agile, less costly and more effective to coordinate the individual preferences to learning with the needs of the markets. The second one, because ethics demands defending an educational system based on liberal principles, without the meddling of a statist education.

Key words: Education and Liberalism, Education and Socialism, evolutionary and anarcho-capitalism basis of the Austrian School for a free education.

JEL Classification: 120, 121, 128.

\section{INTRODUCCIÓN AL ANÁLISIS EDUCATIVO DESDE UNA VISIÓN LIBERAL}

La educación es, de hecho, una de las piezas básicas del liberalismo clásico. Pero debe destacarse que las ideas no flotan libremente en el vacío, sólo tienen capacidad de influir en la medida que son adoptadas y propuestas por los ciudadanos. Así, pues, para que acabe de imponerse la idea de la libertad debe existir un grupo activo de libertarios totalmente entregados a esta causa, gente bien formada e informada en el ideario de la libertad y dispuesta a difundir este mensaje.

Murray N. Rothbard

\section{Introducción}

El liberalismo, ya desde los economistas clásicos, demostró una gran sensibilidad por los aspectos educativos, muy en concreto en lo que refiere a su defensa a ultranza de una educación en libertad. Libertad que siempre ha estado unida a una clara apuesta 
por la educación privada, incluso aun cuando ésta institucionalmente fuese ejercida por el estado, los economistas clásicos defendían que ello no debería mitigar los derechos de las familias y los ciudadanos a recibir con toda libertad una educación acorde con sus deseos individuales.

Sin embargo, en la realidad de los últimos ciento cincuenta años, la extensión de la educación pública y sus crecientes consecuencias negativas ha levantado de nuevo todas las alarmas, en un intento por reconducir las políticas educativas a aquellas situaciones anteriores de educación independiente de las que nunca debió haber salido.

Si bien es cierto que los primeros economistas liberales ingleses, ya en los inicios de la industrialización abogaban por una extensión de la educación que diera respuesta a los desafíos que ésta presentaba; en ningún momento pensaban que dicha extensión de la educación debía transformarse y ser dirigida mayoritariamente desde una concepción de Educación Pública, como así ha sucedido en los últimos ciento cincuenta años. Veamos a continuación una pequeña sinopsis de la importancia que ya desde sus orígenes tuvo la educación para el liberalismo clásico, así como también los efectos negativos que ha tenido para la enseñanza en su conjunto, el ser ésta diseñada y dirigida desde una concepción de Educación Pública.

\section{La importancia de la Educación para el Liberalismo}

En lo que refiere al tema de la Educación, ya en su concepción originaria los economistas clásicos destacan dos variables. La primera de ellas hacía referencia al carácter utilitarista de la misma como medio para el desarrollo de habilidades sociolaborales prácticas (podía mejorar la productividad en la incipiente división del trabajo, mitigar los conflictos en el ámbito laboral y, como consecuencia, aumentar los efectos positivos en la economía). La segunda variable de suma importancia para el liberalismo clásico se refería a la importancia que la educación podía tener como medio para desarrollar la libertad individual. Era tal la importancia que los economistas clásicos daban a la educación 
en libertad, que distinguían claramente entre educación obligatoria y escolaridad obligatoria, razón ésta por la que daban siempre a las familias todo el protagonismo ante la educación de sus hijos.

Para economistas clásicos como Adam Smith (1723-1790), ${ }^{1}$ la educación podía servir para extender y consolidar las virtudes cívicas y morales de la gente. Por su parte Thomas Robert Malthus (1766-1834), ${ }^{2}$ afirmaba con que una población instruida, al ser más consciente de las consecuencias de sus actos, ello frenaría, entre otras cosas, el crecimiento de la población. Años más tarde para Nassau W. Senior (1790-1864), ${ }^{3}$ la educación, además de útil para mejorar las destrezas laborales, podía servir también para sensibilizar a las gentes en la importancia que el ahorro tendría para las familias en su futuro, lo que como consecuencia, haría aumentar en la sociedad los índices de propiedad privada. Por su parte, para John Stuart Mill (1806-1873), ${ }^{4}$ la educación abierta a toda la sociedad incidía fundamentalmente en una mayor igualdad entre hombres mujeres, pero también podía servir para desarrollar un mayor entendimiento entre las clases obreras y los empresarios.

Es decir, en su concepción utilitarista de la educación, los economistas clásicos tenían claro que ésta, por una parte podía mitigar el desorden y los problemas sociales; en tanto que por otra, la educación podía aumentar los efectos positivos en las personas, en la sociedad y en la economía.

Si bien se sale del listado de los principales autores liberales de la época, no quiero aquí dejar de hacer mención expresa a uno de los pensadores más sensibles con el hecho educativo del siglo XIX, me a refiero a Friedrich Wilhelm Christian Carl Ferdinand, Barón de Humboldt (1767-1835). Sin lugar a dudas Humboldt tiene en su hacer educativo sus claros y sombras, pero fue todo un ejemplo para su época (no sólo para Alemania), de lo que significaba la materialización de un modelo claro de políticas y

\footnotetext{
1 Smith, A. (2004 y 2011).

2 Malthus, T.R. (2010).

3 Senior, N.W. (1836).

${ }^{4}$ Mill, J.S. (2008).
} 
estructuras educativas de estado en sus tres niveles de primaria, secundaria y universidad. ${ }^{5}$

Sintetizando podríamos afirmar que para los liberales clásicos la importancia de la educación la resumían en dos palabras: utilidad y libertad. Por una parte la enseñanza pública debía servir para instruir; pero sin que ello fuese óbice para que los padres tuviesen en todo momento el protagonismo sobre la educación, ya que para estos autores era en este apartado donde residía el origen de un pensamiento libre y, por tanto, de una sociedad libre. La grandeza de estos padres del liberalismo fue, que al unir utilidad con libertad individual, afirmaban (como después ha demostrado la realidad de los países socialistas), que no era posible conseguir naciones desarrolladas (aunque sus gentes estuviesen instruidas) en sociedades sin libertad.

Sin embargo, como veremos más tarde, ello no ha sido óbice para que el socialismo en la mayoría de los países democráticos (a pesar de las derrotas sufridas en el siglo XX), a través de sus políticas intervencionistas haya continuado controlando la Educación. En este sentido, en los últimos ciento cincuenta años (muy concretamente en los países europeos), los partidos socialdemócratas a través de sus políticas de Educación Pública, no han cesado de avanzar en sus objetivos de imponer una planificación centralizada de la Educación. ${ }^{6}$ Pasemos a continuación a describir algunos de los principales hitos de dicho proceso histórico y el aumento incesante de consecuencias negativas que ello ha ido generando en las sociedades desarrolladas.

${ }^{5}$ Humboldt, W.V. (2009).

${ }^{6}$ Delibes, A. (2007). En este artículo la autora expone el proceso seguido por las políticas educativas españolas durante los últimos doscientos años (desde el Trienio Liberal, 1820-1823, hasta el presente), y de cómo durante este tiempo en España va desapareciendo, en materia de instrucción pública, todo principio liberal. http:/ / www.liberalismo.org/articulo/401/46/desaparicion/pensamiento/liberal/educacion/ 


\section{Evolución de la Educación Pública en Europa durante los siglos XIX y XX}

A lo largo de los siglos XIX y XX en la medida que fue avanzando la industrialización en Inglaterra, la educación se fue «Externalizando» paulatinamente de las familias al estado. Es decir, fue pasando de una educación privada en donde el control de la misma lo tenían los padres, a una educación de carácter mayoritariamente público, en donde el control lo ejercían las instituciones políticas. Es conveniente resaltar algunos datos relevantes de dicho proceso histórico, por ejemplo ${ }^{7}$ :

— En la Inglaterra de primeros de 1800 la mayoría de la gente sabía leer.

- En 1820, 1 de cada 15 personas asistía a la escuela, y en 1851, 1 de cada 6; produciéndose en este periodo el mayor crecimiento de las escuelas independientes.

- En 1833 se implantó la ayuda estatal a las escuelas.

- En 1870 se crean las Escuelas Públicas, se aprueban sus recursos financieros, humanos y fiscales, así como el Departamento de Educación encargado de detectar las lagunas educativas en todos los distritos.

- Pronto las escuelas privadas advierten sus dificultades para competir con la públicas, dados los fondos públicos que les llegan vía impuestos y ayudas públicas.

- Los argumentos de la escuela pública para definir y detectar lagunas en la educación privada eran:

- Bajo nivel de asistencia escolar (no era por negligencia de los padres, y además, la no asistencia era similar en las escuelas públicas y por las mismas causas de necesidades familiares).

7 West, E.G. (1994). En este apartado se estudia el caso de Inglaterra magistralmente expuesto por el autor y que puede extrapolarse al resto de los países europeos. Para una mayor profundización del proceso de usurpación de la educación privada por parte de la educación pública estatal, consúltense los capítulos IX al XII. 
- Abandono temprano de la escolaridad (situaciones y razones similares a las existentes en el anterior apartado).

- Enseñanza de baja calidad (sin embargo en la escuela pública se cambió razonamiento por memorización, particularización por estandarización).

- Hasta 1870 las escuelas se financiaban a través de: suscripciones, tasas y ayudas estatales; a partir de 1870, además, con impuestos locales. $^{8}$

- A partir de 1902 las escuelas públicas quedaron sometidas a las autoridades locales (más de 330); se introdujeron las ayudas a la formación secundaria y superior (al margen de los niveles de pobreza) y se establecieron las escuelas «gratuitas».

- Las escuelas se diferenciaban por ser:

- Públicas (gratuitas).

- Concertadas (semigratuitas).

- Independientes (costes privados).

- Todo ello dio lugar a la politización del modelo educativo de elecciones escolares caracterizado por:

- Votaciones (valoraciones por largos periodos en vez de por continuados criterios de mercado típicos de los padres).

- Colectivos de presión (fuertes en función de su capacidad organizativa - profesores, sindicatos, etc. - a diferencia de los padres, más individualistas)

- «Paquetes escolares» (se votan planes educativos «precocinados» sin capacidad de elección de los padres). ${ }^{9}$

8 Dicey, A.V. (1952, p. 278): «La abolición de las tasas escolares se armoniza muy bien con las ideas colectivistas. Significa que A, que educa a sus hijos por cuenta propia, o no tiene hijos que educar, se ve obligado a pagar por la educación de los hijos de $\mathrm{B}$, quien, aún teniendo medios para hacerlo, prefiere que el pago provenga del bolsillo de sus vecinos». (Citado en E.G.West, p. 214).

9 West, E.G. (1994, p. 227): «La filosofía educativa se describía como orientada al alumno, ponía énfasis en "proyectos", "métodos heurísticos", "autoaprendizaje". Había que evitar ante todo por parte de los profesores la "enseñanza didáctica" que implicara la transmisión de un cuerpo sistemático de conocimientos. Los exámenes debían 
— La reforma de 1944 añadió aspectos tales como:

- Gratuidad total de las escuelas secundarias.

- Creación de guarderías infantiles a menores de 5 años.

- Aumento de la edad mínima para dejar la escuela hasta los 16 años.

- Etc.

- Argumento central de las instituciones estatales de educación: un sistema general, público y centralizado ${ }^{10}$ es cualitativamente mejor que los demás.

Conclusión: ante lo sucedido bien podríamos afirmar, que proporcionar educación «gratuita» por medio de un proceso político que la gente con anterioridad ya obtenía por sus propios medios y con más libertad y control directo, no constituyó un reforma, sino una mera «re-forma».

Más bien al contrario, las consecuencias de las políticas educativas públicas que durante los últimos ciento cincuenta años se han ido implantando en los países europeos han sido y son realmente preocupantes. ${ }^{11}$ Baste citar, y sin ánimo de ser exhaustivo, los siguientes efectos perversos:

- Imparable crecimiento de los presupuestos públicos en educación, pero también familiares.

ser desprovistos de importancia o mejor eliminados. Las asignaturas clásicas debían irse desplazando por otras tales como: "estudios para la paz", "conciencia social", etc. Era evidente que las propuestas "innovadoras" revestían claros intereses políticos».

10 West, E.G. (1994, p. 29): «La historia de la educación estatal bien podría ilustrar la manera en que las sociedades se engañan fácilmente respecto a sus propias instituciones, debido al insuficiente e inconstante análisis de los argumentos y pruebas que supuestamente las fundamentan. Una vez lanzada una institución estatal, independientemente de su justificación inicial, existe el peligro de que el primer esfuerzo político adopte un impulso propio, creciendo más allá de toda proporción».

11 Maloberti, N. Un argumento contra la educación pública. En este articulo el autor desmonta de una manera pormenorizada los principales argumentos de los defensores de la educación pública: obligatoriedad de la enseñanza, «gratuidad» pública, regulación de contenidos, certificación de títulos, etc. http:/ /www.liberalismo.org/ articulo/213/46/argumento/educacion/publica/ 
- Imposición de la escolarización por encima de la educación.

- Imposición de modelos educativos excluyentes (prohibición de educación en casa, ${ }^{12}$ de educación diferenciada, etc.).

- Baja calidad de la enseñanza. ${ }^{13}$

- Violencia en las aulas.

- Baja transparencia y autonomía colegial.

- Quejas de empresas y alumnos por una educación poco útil.

- Alto abandono escolar.

- Descontento de los padres por su limitadísima capacidad de elección y decisión educativa.

— Descontento de las familias por un «sistema» del cual pueden entrar pero difícilmente salir, ya que las alternativas son pocas o muy costosas para dichas familias.

- Ideologización de los contenidos formativos (historia, filosofía, Epc's, etc.).

- Etc.

Llegados a este punto, no queda más remedio que recordar a los clásicos economistas citados en el apartado anterior, por la clara diferenciación que hacían entre educación obligatoria y escolaridad obligatoria. Entre el protagonismo de los padres (y los propios alumnos) en la elección de sus modelos educativos de carácter privado y los impuestos de manera generalizada en la educación pública. Entre la diversidad (y por tanto, competitividad) existente en una educación de carácter privado y la ausencia total de diversidad existente en la educación pública, etc. ${ }^{14}$

12 Mascaró, L. (2010). En este artículo la autora denuncia la persecución de los padres que educan a sus hijos en casa, hecho que por desgracia existe en otros países europeos, entre ellos España. http://www.juandemariana.org/comentario/4484/ alemania/libertad/educativa/

13 Delibes, A. (2007): «Por otra parte, la filosofía pedagógica que domina hoy en el terreno de la educación sigue siendo de inspiración puramente roussoniana: educar es más importante que instruir, el niño debe construir sus propios conocimientos, el profesor nunca ha de forzar al niño sino acompañarle en su autoaprendizaje, la disciplina no se ha de imponer, la enseñanza memorística y abstracta no sirve para nada, los exámenes son una rémora autoritaria y sólo sirven para traumatizar al alumno».

14 Mill, J.S. (1962, p. 239): «Un sistema de educación estatal es simplemente un medio para producir personas según el mismo molde, y puesto que el molde es el que 
En otras palabras, vistas desde una perspectiva liberal las consecuencias negativas que ha tenido y tiene la educación pública, parece claro el poder afirmar que fuera del marco de una educación privada no es posible una educación de calidad y menos aún, una educación en libertad.

En el siguiente cuadro (Figura 1) se sintetizan las ideas centrales expuestas en el presente apartado.

\section{FigURA 1}

\section{INTRODUCCIÓN AL ANÁLISIS EDUCATIVO DESDE UNA VISIÓN LIBERAL}

- Los economistas clásicos apostaban claramente por una educación privada, y en cuanto a la pública, diferenciando siempre entre educación obligatoria y escolaridad obligatoria (A. Smith, T. Malthus, N.W. Senior, J.S. Mill, etc.).

- A lo largo del siglo XIX y XX en la medida que fue avanzando la industrialización en Inglaterra, la educación se fue «Externalizando» paulatinamente de las familias al Estado. Es decir, fue pasando de educación privada en donde el control de la misma lo tenían los padres, a una educación de carácter mayoritariamente público, en donde el control lo ejercían las instituciones políticas.

- Las consecuencias de dichas políticas educativas públicas que durante los últimos ciento cincuenta años se han ido implantando en los países europeos han ido generando año tras año múltiples efectos negativos en los colegios, familias y alumnos.

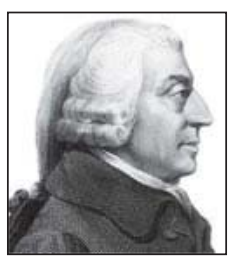

Adam Smith (1723-1790)

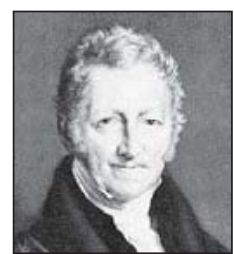

T.R. Malthus (1766-1834)

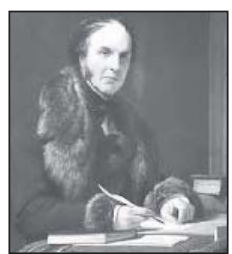

N.W. Senior (1790-1864)

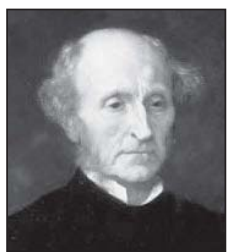

J.S. Mill (1806-1873)

prefiere el poder predominante en el gobierno, sea éste un monarca, el clero, una aristocracia, o la mayoría de la generación existente, en la medida en que sea eficiente y triunfe, conduce a un despotismo sobre la mente, que a su vez conduce naturalmente a un despotismo sobre el cuerpo». (Citado en E.G. West, p. 159). 


\section{PRINCIPIOS TEÓRICOS DE LA ESCUELA AUSTRIACA DE ECONOMÍA: SUS PRINCIPALES AUTORES Y CORRIENTES DE PENSAMIENTO}

\section{La propiedad, por tanto, como economía humana, no es una invención arbitraria sino más bien la única solución práctica posible del problema que la naturaleza nos ha impuesto por la disparidad entre la necesidad y las cantidades disponibles de todos los bienes económicos.}

Carl Menger

\section{Introducción}

Una educación en libertad nos exige, por una parte, ser enormemente cautos en cuanto a los modelos educativos a partir de los cuales conformamos nuestras identidades individuales y desarrollamos nuestras propias potencialidades. En este sentido la corriente evolucionista de la Escuela Austriaca de Economía es para nosotros un referente fundamental a la hora de extraer de ella algunos de los principios pedagógicos para una educación en libertad.

Pero por otra parte, para luchar contra el omnipresente estado que no deja de crecer y nos impone una educación y estructuras educativas de carácter claramente colectivista, esta realidad nos exige dar un claro paso al frente de carácter libertario. Aquí, la corriente anarcocapitalista austriaca es para nosotros un acicate contra el permanente objetivo del estado de imponer a los ciudadanos una "planificación central de la educación». Viendo lo que ha sucedido en los últimos ciento cincuenta años en Europa con las políticas de Educación Pública, muchas son ya las consecuencias negativas recabadas para poder afirmar que una educación libre sólo es posible si está separada del estado. 


\section{La corriente evolucionista: sus principales autores y conclusiones teóricas}

Hablar de los orígenes de la Escuela Austriaca de Economía y de sus principales autores, implica comenzar por Carl Menger (1840-1921), al cual se le considera su fundador. Por supuesto que en la Escuela Austriaca de Economía hay otros autores muy importantes (Friedrich von Wieser, Eugen Bohm-Bawerk, etc.), pero aquí quiero centrarme en los tres más importantes: Carl Menger, Ludwig von Mises (1881-1973) y, Friedrich August von Hayek (1899-1992).

En 1871 Carl Menger publica Principios de Economía politica, ${ }^{15}$ fecha considerada como el nacimiento de la Escuela Austriaca de Economía. En esta obra Carl Menger expone los principios de su teoría económica, a saber:

- El subjetivismo (concepto base explicativo de la acción humana y de su teoría subjetiva del valor).

- Teoría del intercambio (base para el desarrollo de su teoría de los precios).

- Teoría de la evolución de las instituciones económicas (el dinero y el mercado).

- El tiempo (como factor clave en todas las interacciones humanas en un sentido praxeológico).

Analicemos a continuación un poco más pormenorizadamente cada uno de estos apartados.

Para Menger, el subjetivismo es el método adecuado para la investigación en las Ciencias Sociales. Es decir, es el individuo cuando actúa e intercambia el que origina todos los procesos sociales; por lo que, a la hora de analizar dichos procesos, el científico deberá observarlos siempre desde el concepto de acción subjetiva.

Del mismo modo, Menger afirma que la persona por si misma no puede siempre dar respuesta a todas sus necesidades, por lo que para ello la forma más segura es hacerlo a través de procesos

\footnotetext{
${ }^{15}$ Menger, C. (1997)
} 
de libre intercambio de bienes con otras personas que tengan bienes y necesidades complementarias. ${ }^{16}$

En este sentido, Menger siempre habló de la importancia que tenía en los intercambios la pre-visión al respecto de los bienes a intercambiar (lo que más tarde Mises y Hayek definirían como cataláctica), ya que toda acción humana se desarrolla de manera racional en entornos de intercambio (mercados) y cálculos económicos (coste-beneficio) en función de un valor subjetivo a conseguir en cada caso y circunstancia. Es decir, en las acciones humanas ni los fines ni los medios están dados, sino que son descubiertos por el deseo de mejora futura que cada persona tiene a lo largo de su existencia (lo que Mises y Hayek definirían como función empresarial). Es decir, acertar en los procesos de intercambio no es automático, implica conocer las cambiantes necesidades y posibilidades del otro, incluso descubrir previamente dicha información y el valor de la misma (efecto aprendizaje) para actuar coordinada y eficazmente con las necesidades de los demás. ${ }^{17}$

En cualquier caso hay que decir, que si bien este aspecto de la búsqueda de respuesta a las propias necesidades del individuo a través del intercambio con otros está descrito por Menger en su obra, el cómo evolucionan históricamente dichos procesos, fueron más tarde desarrollados de una manera más rigurosa por sus dos principales discípulos: Mises y Hayek. Mises centró sus desarrollos teóricos en la acción humana, en tanto que Hayek lo hizo a través del estudio de la evolución de las instituciones sociales.

Para Mises la acción humana está siempre orientada a satisfacer las necesidades del individuo, bien de una forma intrapersonal (autista), bien de una forma interpersonal (intercambio social).

16 Menger (1997, p. 240): «El principio que induce a los hombres al intercambio no es otro sino aquel que guía su actividad económica en general, esto es, el deseo de satisfacer sus necesidades de la manera más perfecta posible. El placer que experimentan en el intercambio económico de bienes es aquel sentimiento general de alegría derivado de cualquier suceso a través del cual sus necesidades quedan mejor satisfechas que si no se hubiera producido este evento».

17 Menger (1997, p. 144): «Es, con todo, claro indicio de la gran importancia práctica que tiene un exacto conocimiento de la cantidad de bienes de que dispone un individuo el hecho de que una parte muy importante de los comerciantes, industriales $\mathrm{y}$, en general, de personas que desarrollan una alta actividad previsora tienen buen cuidado de adquirir aquel conocimiento». 
Esta última forma de acción humana al tener un carácter de cooperación entre personas, convierte la relación de intercambio en la relación social por excelencia. Para Hayek, esta relación social en la medida que sirve a las personas y grupos para dar respuesta eficaz a sus necesidades poco a poco se va institucionalizando, dando lugar con ello a lo que él define como «instituciones sociales evolutivas». Es decir, para Hayek los procesos espontáneos de intercambio que de manera repetida tienen éxito van lentamente evolucionando hasta conformar órdenes sociales de comportamiento, dando lugar con ello a instituciones sociales de carácter jurídico y económico, entre las que podríamos citar, por ejemplo, el derecho privado, el mercado y el dinero. ${ }^{18}$

Por último, tanto para Menger como para Mises y Hayek la acción humana se desarrolla en un tiempo subjetivo (pasadopresente-futuro), ${ }^{19}$ es decir praxeológico, por lo que la temporalidad de la acción al estar cargada de incertidumbre, es consecuente con las necesidades y expectativas que en cada momento surgen al ser humano.

Por tanto, para Menger (y por extensión para toda la Escuela Austriaca) el punto de partida de toda la ciencia social es la propia acción humana y cuya metodología de análisis integra los tres niveles descritos:

1. El análisis de la acción humana

2. Las relaciones de intercambio y,

3. Las instituciones sociales evolutivas.

18 Martínez Meseguer, C. (2009), Capítulos XII, XIII, XIV y XV. En estos capítulos el autor profundiza ampliamente sobre las principales instituciones sociales evolutivas: el lenguaje, el derecho, el mercado, el dinero, etc.

${ }_{19}$ Huerta de Soto, J. (2010, pp. 45 y 46): «Según esta concepción subjetiva del tiempo, el actor siente y experimenta su transcurso conforme actúa, es decir, conforme, y de acuerdo con la esencia de la función empresarial va creando, descubriendo o, simplemente dándose cuenta de nuevos fines y medios. Se produce así, de forma continua en la mente del actor una especie de fusión entre las experiencias del pasado (siempre subjetivas) que recoge en su memoria y su proyección simultánea y creativa hacia el futuro en forma de imaginaciones o expectativas. Futuro éste que jamás se encuentra determinado, sino que se va imaginando, creando y haciendo paso a paso por el actor». 
Estas tres variables y sus desarrollos posteriores han permitido a la Escuela Austriaca hacernos más conscientes del devenir histórico y, por tanto, más prudentes ante la asunción de teorías y leyes, que si bien afirmaban significar grandes avances, al no estar basadas en acuerdos espontáneos tamizados por el tiempo, eran difícilmente creíbles (como por desgracia han puesto de manifiesto algunas ideologías durante los siglos XIX y XX, muy en concreto el comunismo y el nacionalsocialismo).

En este sentido la Escuela Austriaca con su metodología evolutiva de análisis de las ciencias sociales, a la hora de diseñar o rediseñar las instituciones sociales, sobre todo ha puesto de manifiesto la importancia que tiene poner límites a la razón, diferenciar entre verdad y certeza, leyes y mandatos, ética y estética, evoluciones paulatinas y constructivismos sociales, etc., aportando para ello una epistemología de carácter evolutivo, a partir de la cual poder hacer un análisis del discurso científico más riguroso y prudente con los postulados de las ciencias sociales. ${ }^{20}$

Cesar M. Meseguer ${ }^{21}$ refiere de una manera muy gráfica la importancia que tiene poner límites a la razón a la hora de analizar la evolución de la historia bio-psicosocio-económica de la especie humana, y lo hace del siguiente modo (Figura 2).

Llama la atención que de los seis apartados de este proceso, si exceptuamos el primero (la base genética recibida hereditariamente por cada persona), directa o indirectamente, el resto de los apartados podríamos entenderlos como partes de procesos educativos existenciales que han ido ocurriendo tanto individual como socialmente a lo largo de toda la evolución de la especie humana.

20 Huerta de Soto, J. (1994), Capítulo 1, p. 50: «En suma, podríamos concluir definiendo la sociedad como un proceso (es decir, una estructura dinámica) de tipo espontáneo, es decir, no diseñado conscientemente por nadie; muy complejo, pues está constituido por millones de personas con una infinita variedad de objetivos, gustos, valoraciones y conocimientos prácticos; de interacciones humanas (qué básicamente son relaciones de intercambio que se plasman en precios monetarios y se efectúan según unas normas, hábitos o pautas de conducta); movidas todas ellas por la fuerza de la función empresarial; que constantemente crea, descubre y transmite información, ajustando y coordinando de forma competitiva los planes contradictorios de los individuos; y haciendo posible la vida en común de todos ellos con un número y una complejidad y riqueza de matices y elementos cada vez mayores».

21 Martínez Meseguer, C. (2009, p. 301). 
FIGURA 2

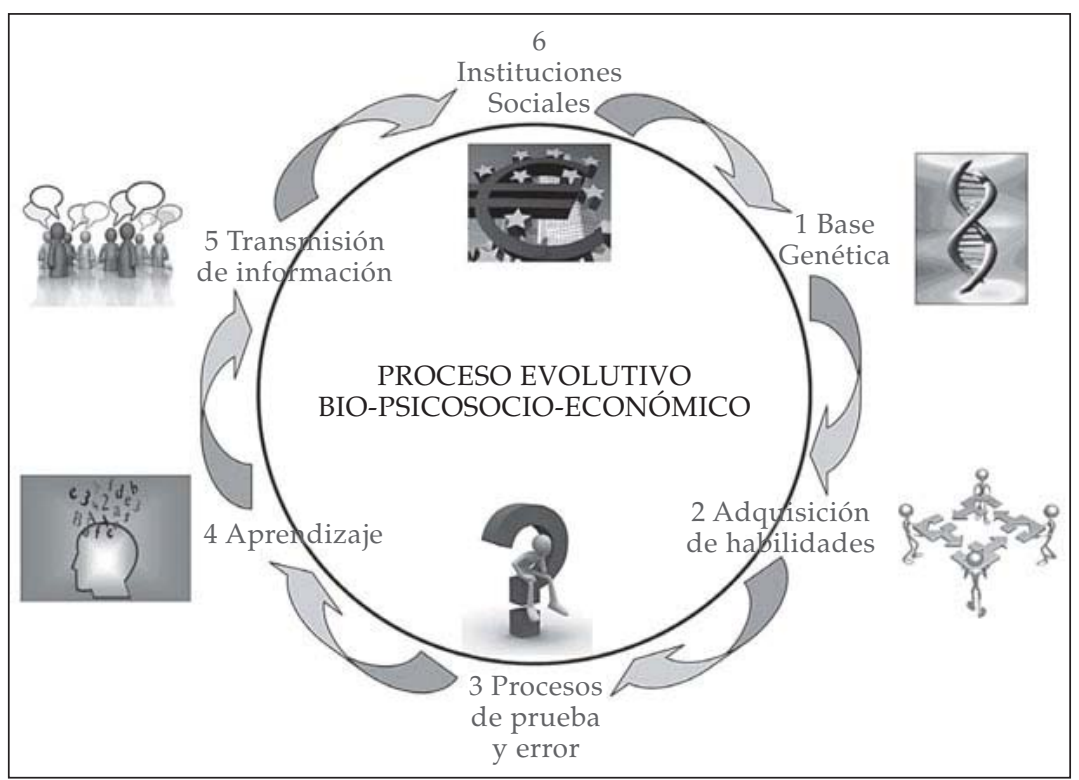

Es decir, el avance racional del hombre no solamente es en sí mismo un proceso evolutivo perceptible a través de su historia, sino que el mismo no se hubiera podido realizar, si la educación como proceso evolutivo no hubiese tenido un desarrollo paralelo. Ni siquiera el lenguaje verbal es una característica exclusiva de la especie humana (algunas especies de loros también "hablan"), pero ninguna especie animal ha convertido al lenguaje en una institución de carácter evolutivo, como así ha sucedido en la especie humana. Y ello se ha debido fundamentalmente a la educación subyacente que existe en toda acción humana. Es decir, todas las especies vivas intercambian información, pero ello no es suficiente para que dichos intercambios per se, por sí mismos, acaben conformando una institución de carácter evolutivo. Eso únicamente ocurre en la especie humana, y no solamente por el mero intercambio de información, sino y sobre todo, por la educación a partir de la cual dicha información es transmitida.

Por tanto, tal vez no sea exagerado definir a la educación como una institución social básica sin la cual las demás no hubiesen 
podido desarrollarse. ¿Es exagerado pensar que el ser humano es en esencia una especie educadora? ¿Habríamos podido llegar a donde hemos llegado si no hubiese sido gracias a ello? Si viésemos la historia de la especie humana como una historia educadora, tal vez tendríamos otra visión de nosotros mismos. No es posible en el presente trabajo profundizar en la historia de la educación humana, dada su complejidad y extensión, pero si queremos entender los procesos que han permitido la generación de nuestras instituciones sociales evolutivas, es inevitable profundizar en dicho recorrido.

La verdad, es que cuando la educación como proceso evolutivo la percibimos como una institución social, no solamente nos percatamos de la importancia de la misma como protagonista esencial que nos ha permitido evolucionar más que cualquier otra especie terrestre, sino que percibimos la gran importancia que tiene para nosotros (como personas y sociedad), el poder llegar a entender las claves educativas, pues ello nos permite un mejor desarrollo bio-psicosocio-económico de nuestros procesos evolutivos.

En este sentido, como ya expusimos en la introducción, los economistas liberales clásicos, aunque no profundizaron en el hecho educativo, ya intuían las repercusiones que tenía, no sólo para la persona, sino para la sociedad y su economía una educación en libertad. No es por casualidad que en todas las épocas de la historia las culturas económicamente más florecientes han sido paralelamente las más educadas. Y a la inversa, tampoco es casualidad ver cómo países materialmente ricos no salen de la pobreza (o vuelven a ella), como resultado de una degradación o ausencia de políticas educativas eficaces. Por tanto, cuando de educación hablamos, no es indiferente unas orientaciones o políticas educativas que otras. Detectar las claves que posibilitan su eficacia bio-psico-socio-económica es fundamental para el éxito de las sociedades.

En este sentido, la corriente evolucionista de la Escuela Austriaca de Economía aporta un gran valor teórico a la hora de investigar el hecho educativo, ya que no sólo nos describe las claves evolutivas que nos permiten entender nuestro desarrollo biopsicosocio-económico como especie humana hasta el presente; sino que nos pone en guardia de los peligros que corremos como 
personas y sociedad, cuando de manera instrumental utilizamos la educación para el diseño de utópicas ingenierías sociales.

\section{La corriente anarcocapitalista: sus principales autores y conclusiones teóricas}

La Escuela Austriaca de Economía, más allá de sus principios y autores originarios como los explicitados en el subapartado anterior, ha tenido desarrollos teóricos singulares en algunos otros ámbitos concretos de la política y la economía, como es el caso que nos ocupa en su vertiente libertaria antiestatista.

En este sentido, si bien hay varios autores significativos a partir de los cuales va configurándose históricamente el anarcocapitalismo: John Locke (1632-1704), Gustave de Molinari (1819-1912), Lysander Spooner (1808- de 1887), etc.; es con Murray N. Rothbard (1926-95), ${ }^{22}$ cuando el libertarianismo adquiere suficiente base teórica como corriente propia dentro de Escuela Austriaca de Economía. Me centraré en este último autor.

El libertarianismo o anarcocapitalismo, como también se le denomina, centra sus principales valores en los derechos de propiedad individual y en la defensa a ultranza de los mercados libres y contratos voluntarios. Su ética podría resumirse en la propiedad de uno mismo y en la prohibición de cualquier forma de coacción o fraude contra las personas y sus propiedades, fundamentándose dicha ética en el derecho iusnaturalista. En cuanto a su objetivo final podríamos sintetizarlo en maximizar la libertad, la prosperidad y la seguridad individual, en paralelo a la abolición del estado, ya que para el anarcocapitalismo dichos objetivos son incompatibles con la existencia de dicho estado. ${ }^{23}$

22 Rothbard, Murray N. (1995).

23 Rothbard, M.N. (1995), capítulo 21, p. 226: «El sociólogo alemán de siglo XIX Franz Oppenheimer describió sucintamente el tema cuando puso de manifiesto que hay dos modos, y sólo dos, de alcanzar riqueza en la sociedad: a) mediante producción y libre intercambio con otros (el método del libre mercado); y b) mediante expropiación por la fuerza de la riqueza producida por otros. El primer beneficia a todos los participantes; el segundo beneficia parasitariamente a la clase o al grupo saqueador a expensas de los saqueados. Oppenheimer denomina tajantemente al 
Siguiendo al anarcocapitalismo, pero entrando ya en el tema de la educación, podemos decir que uno de los ámbitos de la persona en donde se expresa de una manera más clara la libertad individual es en su libertad de pensamiento. Libertad de pensamiento que sin lugar a dudas tiene su principal origen en la libertad educativa. Difícilmente podemos imaginar una persona de pensamiento libre desarrollada en un entorno de educación no libre.

En este sentido, por tanto, también podemos sospechar, que si el Estado a través de sus mil formas distintas de intervencionismo puede coartar las libertades individuales, igualmente lo puede hacer con la educación. Cosa que de hecho hace, ya que es a través de la educación (en sus más variadas formas) cómo el Estado puede controlar y orientar el pensamiento de una sociedad. ${ }^{24}$

$Y$ es en este punto, viendo la tendencia que han tenido los estados con sus políticas de Educación Pública al implantar modelos que podríamos definir de Planificación Central de la Educación, cuando los libertarios se hacen la pregunta ¿es posible una educación libre con estado?

Para los anarcocapitalistas puros su respuesta a dicha pregunta es claramente negativa: no es posible una educación libre con estado. Ni libre, ni por lo que la historia reciente parece demostrar, tampoco es posible una educación de calidad. Allí donde no existe un mercado privado de propuestas formativas en libre

primer método de obtención de riqueza "los medios económicos" y al segundo "los medios políticos". Y dando un paso más definió brillantemente al Estado como "la organización de los medios políticos"»".

${ }^{24}$ Rothbard, M.N. (1995), capítulo 21, pp. 229-230: «Reviste particular importancia para el Estado del mundo moderno - en un momento en el que es patente que ya ha dejado de ser viable la iglesia establecida- hacerse con el control del sistema educativo para poder moldear las mentes de sus súbditos. Además de la influencia ejercida en las universidades a través de las múltiples modalidades de subvenciones oficiales y centros de estudios superiores de titulación estatal directa, los gobiernos controlan la educación en sus niveles inferiores mediante las universales instituciones de enseñanza pública, los certificados, los permisos y las condiciones que el Estado impone los centros privados, además de la normativa que fija la asistencia obligatoria a los centros escolares. A todo ello se añade el control virtualmente total de la radiotelevisión, bien porque es de titularidad pública en la mayoría de los países, o bien porque, a través de la nacionalización de las ondas, las autoridades reservan la facultad (por ejemplo en Estados Unidos) de conceder - o de negara los centros emisores privados la utilización de estas frecuencia y canales». 
competencia de modelos, contenidos y precios, no puede desarrollarse una educación de calidad y menos aún en ese contexto, las personas podrán desarrollar su libre pensamiento individual.

En dicha crítica no les falta razón a los anarcocapitalistas, la historia reciente de la Educación Pública ${ }^{25}$ en España y en Europa (y por extensión en occidente), demuestra una clara tendencia a un estatismo centralizador de la educación, y ello ha sido así, indistintamente de sus gobiernos conservadores o socialdemócratas. Los programas, contenidos y modelos educativos estaban y siguen estando centralizados y estandarizados, con muy poca o nula capacidad de decisión de las familias en la marcha de la formación de sus hijos, con una constante desmotivación del alumnado y, una imparable bajada de la calidad de la enseñanza. ${ }^{26}$

Ahora bien, podemos estar de acuerdo con el anarcocapitalismo en cuanto a que un sistema de educación privada, si bien garantiza mejor un verdadero mercado libre de educación, el anarcocapitalismo no acaba de definir con suficiente rigor aún que entiende por «libertad de educación». Visto en sentido amplio, en su concepto de libertad de educación sería posible incorporar en los modelos y programas educativos toda clase de contenidos. Por ejemplo, desde los más democráticos a los más totalitarios. Cierto que sus principios se basan en la no agresión y ausencia de cualquier tipo de coacción en todas las relaciones

25 Rothbard, M.N. (1995), capítulo 29, p. 349: «El sistema de la escuela pública [...] está hoy sujeto a una severa y acelerada crítica popular de todo el espectro ideológico. Se ve ahora claramente a) que las escuelas públicas no educan adecuadamente a sus alumnos; b) que son caras, derrochadoras y exigen elevados impuestos, y c) que el uniformismo del sistema de la enseñanza pública genera profundos e irresolubles conflictos sociales sobre temas educativos vitales tales como integración frente a segregación, métodos progresistas frente a métodos tradicionales, religión frente a laicismo, educación sexual y contenido ideológico de la enseñanza. Sea cual fuere la decisión que el sistema educativo público adopte en estas áreas, se habrán causado graves e irreparables daños a la mayoría o a una gran minoría de padres y niños. Además, se está advirtiendo con creciente claridad que la legislación sobre la asistencia obligatoria a la escuela mete a la fuerza a niños infelices o carentes de motivaciones en una cárcel que no les reforma ni a ellos ni a sus padres».

26 Sotero, P.D. y Suárez, E. (2010): El nuevo estudio PISA consagra el estancamiento de la educación española. El pasado 7 de Diciembre del 2010 los medios de comunicación españoles se hacían eco de los resultados negativos de la educación en España, señalando en el mismo una tendencia al estancamiento en la mayor parte de los países de la OCDE. 
de libre intercambio; pero en el ámbito de la educación, sabemos que la violencia se puede enseñar (y aprender) sin agresión y coacción alguna para con el alumno desde el libre intercambio entre padres y colegios que estén de acuerdo en impartir a los alumnos, por ejemplo, una enseñanza de base ideológica totalitaria. Por tanto, una primera pregunta interesante a la hora de plantear una educación desde la perspectiva anarcocapitalista sería ¿Dónde está en una sociedad libertaria (de contratos libres y ausencia de coacciones), el límite de una educación libre y quienes se encargarían en ausencia del estado de poner dichos límites y controlar que se cumpliesen? Es una pregunta aún sin responder por parte del anarcocapitalismo posiblemente porque la respuesta es obvia: los seres humanos en un entorno de libertad, acuerdos voluntarios y cumplimiento contractual.

Por otra parte, en el mismo Rothbard hay un momento en su discurso de defensa del anarcocapitalismo (en contraste con el resto del discurso austriaco al que dice pertenecer), que pretende defender el concepto de «recta razón», dando a entender con ello la existencia de otra razón «no recta». Esta tendencia a un racionalismo extremo no deja de preocupar a muchos de los seguidores de la Escuela Austriaca de Economía, contrarios a todo concepto de «razón objetiva» (en contraposición al concepto de «razón subjetiva» misiano), pues si bien están de acuerdo con la mayoría de las tesis anarcocapitalistas de Rothbard, en este punto guardan serias reservas, ya que la historia ha demostrado reiteradamente que los discursos basados en el binomio «recta razón» versus «razón no recta» han sido siempre la principal causa del advenimiento de totalitarismos, con todo lo que ello ha significado como legitimadores para sus respectivas reingenierías sociales. ${ }^{27}$

27 Martínez Meseguer, C.M. (2009, pp. 176 a 178): «No debemos olvidar que según Rothbard el hombre a través de la "recta razón" sería capaz de descubrir la Ley Natural Eterna, que vendrá a ser el conjunto de preceptos o dictados universales de esa "razón objetiva" relativos al bien que debe ser perseguido y al mal que debe ser evitado. Esta "razón objetiva" de Rothbard permitiría al hombre según él, una vez que ha conseguido averiguar cual es su propia esencia, establecer las leyes naturales que deben de regir. Esta ley natural aclararía y dictaría qué es mejor para el hombre; es decir, qué fines se deben perseguir por ser los más acordes con su naturaleza, al ser capaz de establecer objetivamente cuales de entre ellos son buenos o son malos. [....] Para Rothbard, una vez que el hombre es capaz de conocer la ley natural [...] es sencillo 
La Escuela Austriaca de Economía siempre ha estado de parte de una actitud humilde en todo lo que refiere a las limitaciones de la mente humana para alcanzar un conocimiento absoluto de las cosas que le rodean. De ahí su defensa a ultranza de una metodología reflexiva de carácter histórico-evolutivo, basada en normas abstractas universales, garantizadoras de una mayor libertad y diversidad, pero en clara contraposición a las racionalistas, ${ }^{28}$ de tipo apriorístico-deductivo y, por tanto, de carácter cientista. ${ }^{29}$

Estas matizaciones son de enorme interés cuando hablamos de educación. La educación es algo más que transmisión de información, conocimientos y técnicas, lo es también de éticas y valores. Éticas y valores a partir de los cuales se conforman las identida-

establecer el Derecho Natural y, por tanto, es necesario que se establezcan las leyes positivas que serán de aplicación a las realidades concretas, agrupándolas en un código legal que, a su vez, será la base del funcionamiento de la sociedad libertaria del futuro (¿?). [....] Se trata, por tanto, de una postura racional-constructivista en sus planteamientos, que basándose en una análisis que pretende ser omnisciente, donde todo está dado y todas las esencias son conocidas (el hombre, la razón objetiva, la moral, el derecho...) y olvidando todo aspecto evolutivo (incluido el de la propia razón), piensa que puede elaborar una ética social objetiva de la libertad, de contenido válido universalmente y para cualquier tiempo y lugar.

28 Hayek, F.A. (1990). Para Hayek el «cientismo» o «constructivismo», se estructura en cuatro importantes conceptos, a saber:

- El racionalismo, solo da validez a lo que tiene por base la experiencia y la razón, sea deductivo o inductivo.

- El empirismo, solo da certeza a algo si se basa en proceso experimental, si se puede comprender.

- El positivismo, solo si el auténtico conocimiento tiene carácter científico, es decir, fenómenos que coexisten, concatenados en el tiempo y siempre observables.

- El utilitarismo, solo son intrínsecamente valiosos para el individuo aquellos actos que conoce de antemano y le son favorables.

Todas estas definiciones coinciden en rechazar la moral tradicional y, por otro lado, critica la idea de que todo lo que no es racionalmente justificable, experimentalmente contrastable, aprehensible por nuestros sentidos, no merece ser creído ni aceptarse si no favorece lo placentero. (Ver Capítulo IV, pp. 109 a 112).

29 Martínez Meseguer, C.M. (2009, p. 180): «por ello el científicos social, desde el punto de vista de la Escuela Austriaca, más que dedicarse a inventar utopías sociales, debería centrar su estudio en los procesos que permiten un mejor desarrollo y evolución de la sociedad y de las instituciones que la estructuran; más que en intentar averiguar que leyes deben ser impuestas, estudiar los caminos que permiten al hombre llegar al descubrimiento y conocimiento de aquellas; más que decidir que hará más felices a los demás, intentar descubrir los medios que puedan permitir con mayor facilidad que cada cual alcance sus propios fines; etc.». 
des individuales y colectivas, muy en concreto cuando los alumnos están en los primeros ciclos de enseñanza. Y aquí de nuevo surge una segunda pregunta de difícil respuesta aún por parte del anarcocapitalismo, al menos hasta el presente. ¿Cómo garantizar una educación libre que esté exenta de todo riesgo de contenido totalitario? Quizás la respuesta sea que la pregunta está mal planteada: el objetivo es impulsar la educación libre y acabar con el estatismo y totalitarismo actual, siendo conscientes de que no hay garantías salvo la certeza de que el proceso de la libertad es superar al sistema actual.

Por último, hay una tercera cuestión de gran importancia cuando queremos plantear una educación desde una perspectiva anarcocapitalista, y es la referida no al control, no a los contenidos, sino a los modelos y niveles de libertad psicopedagógica. La experiencia nos demuestra que no es posible una educación libre con modelos rígidos de enseñanza, pero tampoco con modelos educativos de libertad sin límites. Así por ejemplo, el modelo libertario Summerhill de A.S. Neill, ${ }^{30}$ si bien en su momento fue un revulsivo contra los rígidos modelos de educativos público-privados, dadas sus tendencias anarquistas de carácter izquierdista (Rousseau) y psicoanalíticas (Wilhelm Reich), hoy son modelos pedagógicos ampliamente cuestionados en cuanto a su eficacia educativa para dar respuesta a los desafíos del mundo real. En el otro extremo se encontrarían las experiencias educativas de Corea del Sur (el segundo país mejor puntuado de manera reiterada por los informes PISA), pero en su clara apuesta por la excelencia educativa público-privada es hoy el país con mayor número de suicidios de alumnos del mundo. ${ }^{31}$ Ante ambos extremos

\footnotetext{
30 Neill, A.S. (1986).

31 Rodríguez-Borlado, F. (2011). «Corea del Sur es un país de éxito por su ascenso económico en las últimas décadas, progreso basado especialmente en la excelencia en la educación. Sin embargo, otros indicadores revelan el lado oscuro de ese cambio: un porcentaje muy bajo de satisfacción con la propia vida (36\% frente a una media del $59 \%$ en la OCDE), poca confianza en las instituciones políticas y la tasa de suicidios más alta de la OCDE (31 por 100.000). De fondo, un paisaje de competitividad feroz en el mundo laboral y más aún en la educación. En 2010, según datos del propio Ministerio de Educación, 146 estudiantes se suicidaron en Corea del Sur, incluidos tres de primaria. En un país donde el suicidio está bastante anclado en la cultura, se puede conjeturar que no todos los casos estuvieran relacionados con el asfixiante sistema educativo. Pero el
} 
pedagógicos surge la imprescindible pregunta ¿Qué modelo pedagógico garantizaría mejor el trinomio eficacia educativa - mercado libre de enseñanza - libertad de pensamiento?

Estamos de acuerdo que para el anarcocapitalismo no cabe duda que una educación libre exige en todo momento separar la educación del estado; apostar claramente por la implantación de los mercados privados de enseñanza libre; mercados en los cuales no exista coacción alguna, ni en la forma ni en los contenidos educativos; $y$ en donde el total protagonismo de la enseñanza lo tengan ofertantes y demandantes de la enseñanza.

Ahora bien, defender desde el anarcocapitalismo un riguroso concepto de educación libre, implica contestar a preguntas como las anteriormente expuestas y que algún día habrá que responder convincentemente si como austriacos queremos avanzar en nuestro objetivo de una educación en libertad. Creo que ha llegado el momento para ello.

En la siguiente imagen (Figura 3) podemos ver una síntesis de lo expuesto en el presente apartado al respecto de los dos epígrafes tratados: el evolucionismo y el anarcocapitalismo.

III

\section{EDUCACIÓN Y SOCIALISMO}

Socialismo es todo sistema organizado de agresión institucional contra la función empresarial y la acción humana.

Jesús Huerta De Soto

\section{Introducción}

Tal vez sea oportuno a la hora de hablar de educación y socialismo, recordar aquí las palabras de Hayek: «Cuando hablamos de transmisión y comunicación del conocimiento nos referimos a

propio gobierno de Seúl comienza a dar signos de preocupación. Sobre todo, después de que las últimas muertes salpicaran al Kaist (Instituto Avanzado de Ciencias y Tecnología, en Daejeon), una de las instituciones universitarias más prestigiosas del país». 
FIGURA 3

EDUCACIÓN Y GRANDES CORRIENTES AUSTRIACAS: EVOLUCIONISMO Y ANARCOCAPITALISMO

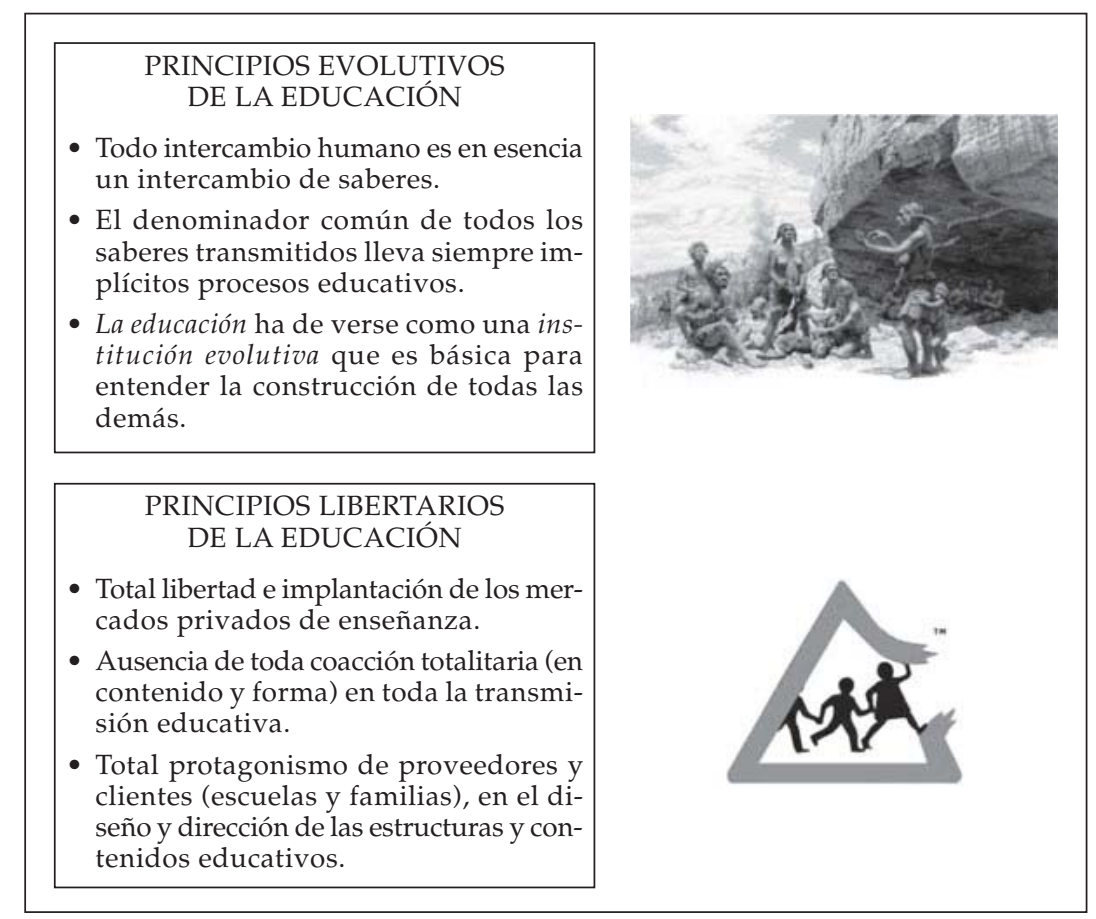

dos aspectos del proceso de la civilización que ya hemos distinguido: la transmisión en el tiempo de nuestra acumulación de conocimiento y la comunicación entre los contemporáneos de información sobre la cual puedan basar su acción». ${ }^{32}$

Ambos aspectos, transmisión de la civilización y comunicación libre entre contemporáneos, son las dos grandes ausencias de toda educación socialista. El socialismo, por una parte, tiene como objetivo fundamental el constructivismo social (contrario a toda civilización heredada), en tanto que por otra, persigue (muy en concreto en los ámbitos educativos) a toda comunicación entre

\footnotetext{
32 Hayek, F.A. (2008)
} 
contemporáneos opuesta a sus tesis ideológicas («Sólo el marxismo es ciencia»). ${ }^{33} \mathrm{El}$ socialismo como racionalismo cartesiano que es, se reafirma en sus razones, las cuales le llevan a negar su ignorancia. Es por ello que al creerse omnisciente, en su «fatal arrogancia» ${ }^{34}$ al adueñarse de la «educación pública», su objetivo no es la búsqueda de conocimientos nuevos en los distintos ámbitos de las ciencias, sino convertir dicha «educación pública» ${ }^{35}$ en el principal instrumento para el adoctrinamiento de sus tesis.

Para el socialismo no existe eso que conocemos como «pensamiento científico» (actitud de permanente búsqueda de la verdad última, lo que implica un continuo contraste de teorías científicas que en su objetivo de ser refutadas, hacen avanzar las ciencias); ellos como constructivistas que son, sólo creen en la «ideologización de las ciencias», por lo que todo su sistema educativo está orientado a conseguir dicho objetivo.

En pocas palabras, el socialismo en su fuero interno funciona como si de una ideología religiosizada se tratara, por lo que a través de la educación no quiere conseguir hombres de pensamiento libre, sino creyentes. ${ }^{36}$

A diferencia del socialismo omnisciente, sorprende cómo para el liberalismo de la Escuela Austriaca la libertad está justamente

33 Mises, L. von (2009, p. 353): «En otros términos, sólo el marxismo es ciencia. Todo lo que ha precedido a Marx es la prehistoria de la ciencia. [...] después de la aparición de Marx, la verdad sólo existe ya entre los marxistas, pues todo lo demás no es más que engaño, ilusión, apología capitalista».

34 Hayek, F.A. (1990)

35 Rodríguez, J.C. (2006). «Ese ideal de educación pública, imposición de valores, forja de súbditos, inculcación de determinados esquemas morales es exactamente lo que tenemos en España. La plasmación más perfecta de ello es la asignatura de Educación para la Ciudadanía. Un documento del Ministerio en el que se basa el programa de la asignatura dice, en ese lenguaje colectivista y totalitario que "la sociedad democrática no puede eludir la tarea de socializar a los niños y jóvenes, proporcionándoles a través del sistema educativo las enseñanzas y la reflexión necesarias..." ».

36 Mises, L. von (2010), capítulo 3, p. 112: «El concepto de valores eternos y absolutos es un elemento indispensable en esta ideología totalitaria. Se instaura un nuevo concepto de verdad. Verdadero es aquello que los que están en el poder dicen que es verdadero. La minoría que disiente es antidemocrática, porque rehúsa aceptar como verdadera la opinión de la mayoría. Todos los medios para "liquidar" a los rebeldes son "democráticos" y por tanto moralmente buenos.» 
legitimada en «la ignorancia» del ser humano. Si lo supiéramos todo no necesitaríamos la libertad, ya que las decisiones adecuadas las conoceríamos de antemano. Es decir, la libertad, como actitud de búsqueda de la verdad descansa en la conciencia de nuestra ignorancia. ${ }^{37}$ Es por ello, por lo que el liberalismo cree que sin libertad educativa no podemos avanzar ni como individuos ni como civilización. A buen seguro que es por ello por lo que el socialismo ataca con tanto encono las instituciones sociales fuentes de la identidad individual (la familia) y de la identidad colectiva que nos aporta las instituciones evolutivas esenciales representativas de nuestra civilización ${ }^{38}$ occidental (en nuestro caso la religión judeocristiana y la cultura greco-romana, con todo lo que ello implica por ejemplo, para la permanencia de nuestro derecho romano, la propiedad privada, el comercio, el dinero, etc.). El socialismo sabe que el triunfo de su constructivismo y reingeniería social sólo es posible si dichas instituciones fundamentales son eliminadas. Y sabe que el instrumento más adecuado para ello es a través de la educación pública.

37 Martínez Meseguer, C.M. (2009), capítulo X, p. 189: «Es decir, conscientes de que la razón es un instrumento básico para el ser humano, pero al mismo tiempo consciente de sus limitaciones. Sabedores de que el hombre como ser imperfecto, limitado y mortal, no puede llegar alcanzar el conocimiento de lo absoluto, pero consciente, al mismo tiempo, de: a) la existencia de realidades de límites físicos, químicos y biológicos externos que el hombre debe interpretar, b) la posibilidad de que se vayan realizando paulatinas aproximaciones a la verdad, y c) de la existencia de leyes y principios generales de tipo formal, que nos sirven de guía en nuestro continuo proceso de conocimiento de la realidad. Siendo además partidarios de un conocimiento subjetivo, que tiene un claro sentido de la creación de modelos y teorías mentales interpretativas, en ese intento de continua aproximación a la verdad, rechazando por tanto el realismo de tipo metafísico, así como el relativismo».

38 Hayek, F.A. (2006, pp. 523 y 524): «... el actual orden social es en gran parte resultado no ya de un plan deliberado, sino del predominio de las instituciones más eficaces en un proceso competitivo. La cultura no es ni natural ni artificial, ni algo genéticamente transmitido o racionalmente diseñado. Es una tradición de normas de comportamiento aprendidas, que jamás fueron inventadas y cuya función no comprenden generalmente los individuos». 


\section{Educación pública y socialismo}

Para los socialistas, como estatistas que son, «educación pública» es un binomio inseparable, de ahí su objetivo de control absoluto de toda la estructura educativa del estado. Pero sería muy ingenuo pensar que para los socialistas la estructura educativa sólo se refiere a las instituciones de enseñanza: para ellos la estructura educativa son todos aquellos medios que pueden ser utilizados para adoctrinar a sus ciudadanos en su dogmas ideológicos.

Sería un error por tanto, cuando hablamos de socialismo y «educación pública», centrarnos solamente en la estructura institucional que va desde la guardería a la universidad. En cuanto a adoctrinamiento ciudadano se refiere, para el socialismo son tan importantes las instituciones académicas como los medios de comunicación de masas (prensa, radio, tv, internet, etc.). ${ }^{39}$ Tanto unos como otros pueden ser utilizados (y de hecho lo son), como púlpitos de adoctrinamiento. Es por ello que los socialistas estén en el gobierno o desde la oposición, siempre tienen como objetivo prioritario el adueñamiento político de todas las instituciones con capacidad de adoctrinamiento. Objetivo que consiguen a través de permanentes reglamentaciones y dirección de dichas instituciones de adoctrinamiento por parte de «intelectuales» elegidos por el socialismo para tal fin..$^{40}$

Pero centrémonos en este momento, cuando de socialismo y «educación pública» hablamos, solamente en su vertiente de enseñanza institucional. Decíamos que para los socialistas «educación pública» es un binomio inseparable. Ya comentamos en el

39 Hayek, F.A. (2006), capítulo XIV, p. 427: «... ciertamente no es deseable que el gobierno asuma una posición dominante en la distribución de las noticias; entregar al gobierno el monopolio de la televisión, como sucede en algunos países, es una de las decisiones políticas más peligrosas de los últimos años.»

40 Mises, L. von (2009): El socialismo. Análisis económico y sociológico. Todos sabemos de la habilidad del socialismo para conformar sus «fuerzas de la cultura» que al modo de «castas intelectuales» hábilmente subvencionadas e introducidas en las instituciones educativas y mediáticas, son convertidas en apóstoles sagrados de los dogmas marxistas. El socialismo se siente legitimado a repartir entre la gente en función de su obediencia a los dogmas marxistas el carné de «intelectual». En este sentido Mises comenta p. 509: «Son los intelectuales los que han sido conquistados por el socialismo. Son éstos y no las masas las que sirven de apoyo al socialismo». 
segundo capítulo las muy negativas consecuencias que ha tenido y sigue teniendo la educación pública estatalizada en Europa y dirigida además, desde una concepción de «Planificación Central de la Educación». ${ }^{41}$ Concepto éste a partir del cual el socialismo orienta y de facto controla la materialización de todo su constructivismo social.

Siempre me ha llamado la atención cómo a lo largo de todo el siglo XX, el comunismo, si bien fracasó con su Planificación Central de la Economía allí donde gobernó; sin embargo, en el capitalismo, la socialdemocracia triunfó plenamente (y sigue triunfando) con su Planificación Central de la Educación (muy en concreto en Europa). ¿Cuáles son las causas de su éxito que no parece terminar? Sin lugar a dudas sus distintas y coordinadas formas de coacción institucional. Veamos algunas.

\section{Socialismo y coacción educativa}

Ya hemos comentado que el socialismo tiene como primera forma de coacción educativa el permanente intervencionismo legislativo sobre la misma. Su constante goteo de órdenes, mandatos, reglamentos, etc., de derecho público, no sólo sirven para imponer y controlar sus políticas educativas, sobre todo, como derecho público que es, sirve fundamentalmente para socavar los derechos privados de familias y alumnos a ser los principales protagonistas de su educación. Por supuesto, no se podrían socavar tales derechos si en paralelo no se estuviese realizando una perversa tarea de reingeniería social sobre la propia institución familiar, proscribiendo cada día más los derechos de los padres sobre los hijos, muy en concreto en lo referente al derecho de dichos padres a ser los principales educadores de sus hijos ${ }^{42}$ (en

${ }^{41}$ Hayek, F.A. (2008), capítulo XIV. p. 488: «La simple posibilidad de que al instaurar un sistema general de educación, controlado por la autoridad, quede la enseñanza elemental, a su vez, sometida a directrices que determinados teóricos señalan debería bastar para ponernos en guardia contra los riesgos que entraña someter el sistema educacional en su conjunto a una dirección centralizada».

42 Rallo, J.R. (2005). «Debemos tener presente que el Estado debe salir inmediatamente de la educación; no se trata de que una mejor ley de educación sea posible, 
la mayor parte de los países europeos, la educación en casa está no solamente prohibida, sino penada por el estado).

Pero el socialismo no solamente coacciona la educación libre con reglamentos, y anulando los derechos de los padres, sino también imponiendo a los alumnos la zonificación de sus centros de estudio, no pudiendo elegir otros que los adscritos por el estado a dichos alumnos.

A lo anterior hemos de unir la totalitaria coacción de imposición de contenidos educativos de claro carácter socialista en todas las asignaturas que dan posibilidad de ello (filosofía, historia, economía, naturaleza, EpC, etc.) y a lo largo de toda la trayectoria curricular del alumno desde la guardería a la universidad (con dogmas tales como el igualitarismo ${ }^{43}$ el ecologismo, el feminismo, el multiculturalismo, el homosexualismo, el anticapitalismo, etc.).

Por parte del socialismo hay otra coacción educativa mucho más dañina aún, y es la que hace referencia al perverso control ideológico del profesorado en todas las instituciones de educación pública. Coacción, que escondida tras la máscara de un sin fin de reglamentaciones académicas, sirven para apartar de la docencia a toda persona que no sea de fiar para el socialismo. ${ }^{44}$ Ello

sino de que la educación debe ser elegida libremente por los padres, sin leyes que la coarten o restrinjan. La familia tiene el derecho a educar a sus hijos no sólo en los valores, también en las materias y contenidos que crea convenientes. De hecho, resulta harto complicado desvincular los valores de los contenidos concretos; para una persona, los valores morales no son más que un reflejo de la verdad, y la verdad es, precisamente, el objeto de la educación.»

43 Hayek, F.A. (2006, Epílogo. p. 547): «Sería realmente una trágica broma de la historia si el hombre que debe su rápido desarrollo únicamente a la excepcional variedad de los talentos individuales, tuviera que terminar su propia evolución imponiendo a todos un esquema igualitario».

44 Penalva Buitrago, J. (2011). En este libro el autor describe su propia experiencia como profesor dentro de la universidad española. Así por ejemplo dice p. 47: «Poco a poco fui percibiendo que todo el entramado estructural en que se asientan los departamentos pedagógicos universitarios es el andamio que posibilita que la ideología se instaure en el pensamiento sobre el sistema educativo» [...] p. 51: "yo ya conocía el género y estaba al tanto de las leyes no escritas (que son las que mueven el cotarro al margen de las leyes oficiales [...] Y hay que tener en cuenta que, durante ese tiempo en el departamento estuvieron entrando como profesores personas que no habían publicado nada; pero nada de nada. Administrativos de ayuntamientos, inspectores asqueados de las escuelas y cosas por el estilo, pero, eso sí, con un pedazo de carné que lo ponen en la mitad de la vía y hace descarrilar trenes. Y también había muchas 
conlleva no solamente coacción a los derechos de dichos profesores, sino y sobre todo, al concepto académico de «libertad de cátedra", con todo lo que ello supone de ataque para una educación en libertad.

Pero no hemos de olvidar que el socialismo con su educación pública también es coactivo con los colegios privados, ya que no solamente impone las mismas reglas de funcionamiento que a los públicos, sino que les castiga con la no concertación y mayores cargas impositivas si no acceden a sus reglamentos de carácter ideológico (por ejemplo, si se aprueba la próxima ley de «Igualdad de Trato» en España los colegios con educación diferenciada serán excluidos de toda concertación... de momento sólo eso).

Pero la coacción educativa del socialismo, no termina en los alumnos, familias, profesores, y colegios privados, se extiende a la sociedad entera, ya que toda ella se ve obligada a sufragar vía impuestos dicha educación pública aunque en paralelo los ciudadanos estén dispuestos a costearse su propia enseñanza fuera del sistema de educación pública.

Para los liberales, ante la constatación de tales coacciones socialistas, ${ }^{45}$ contra los alumnos, las familias, los profesores, los colegios privados (a lo que habría que añadir las negativas consecuencias de la educación pública ya descritas en el capítulo 2.ํ), no cabe otra solución que, primero, desenmascarar la falsedad del binomio educación y pública, y segundo, separar totalmente al estado de la educación. Es inviable una educación en libertad con la existencia de una «educación pública» ordenada bajo el concepto socialista de Planificación Central de la Educación. Justo lo

profesoras que también habían sido becarias...» [...] pp. 116 y 117: «la vida académica en España está enclaustrada en dogmas y autoritarismos. En España en general no existe la crítica y muy en particular en el mundo universitario. Los profesores que se enfrentan a los dogmas vigentes no pueden progresar en la vida universitaria».

45 Hayek, F.A. (2006), capítulo XVIII. pp. 519 y 520: «La última batalla contra el poder arbitrario todavía no se ha librado - la lucha contra el socialismo y a favor de la abolición de todo poder coactivo para dirigir los esfuerzos individuales y distribuir deliberadamente sus resultados. Espero que algún día se comprenda este carácter totalitario y esencialmente arbitrario de cualquier forma de socialismo, como ya lo ha sido el del comunismo y del fascismo, y que por lo tanto se apruebe generalmente la construcción de barreras constitucionales contra cualquier intento de conseguir tales poderes totalitarios bajo cualquier pretexto.» 
contrario que defiende el liberalismo: auténticos mercados libres de educación privada (Figura 4).

IV

EDUCACIÓN Y EMPRESARIALIDAD

La noción de descubrimiento o creatividad, situada a medio camino entre la producción

deliberada de información desarrollada por la teoría convencional de la búsqueda de información y, la ganancia deliberada de la pura suerte, es el eje central del enfoque teórico de los economistas austriacos.

I.M. KIRZNER

FIGURA 4

EDUCACIÓN Y SOCIALISMO

- la transmisión en el tiempo de nuestra acumulación de conocimiento y
- la comunicación entre los contemporáneos de información sobre la cual puedan basar
su acción.
El socialismo impide la realización de ambos aspectos dado que es:
- constructivista (contario a la civilización heredada),
- racionalista (su objetivo es imponer sus tesis, no refutar teorías).
Es por ello que «la educación pública» socialista solo es sostenible como conse-
cuencia de sus sistemáticas formas de coacción institucional:
- coacción a las familias, a los alumnos, a los centros privados, a los ciudadanos en general,
- vía imposiciones como la zonificación, los contenidos curriculares de claro objetivo adoc-
trinador, la obligatoriedad de las cargas impositivas a toda la ciudadanía al margen de
que se eduquen o no en colegios públicos, etc.
Conclusión: la educación libre es imposible en un sistema
de «educación pública» socialista de planificación centralizada.




\section{Introducción}

Si una de las bases fundamentales de la educación para la Escuela de Economía Austriaca hemos visto que es la libertad, sin lugar a dudas otra de ellas es la función empresarial o empresarialidad. Para los austriacos la «acción humana» es el gran secreto a voces que nos ha permitido evolucionar hasta el presente, es decir, de ser lo que somos como especie y culturas.

La «acción humana», como gran motivador del avance humano ha tenido siempre como razón de ser, un espíritu constante de mejora, un estímulo por encontrar fórmulas con las que superar las limitaciones que el hombre encontraba en la naturaleza virgen. Ello le ha permitido superar obstáculos, no sólo de manera individualizada, sino y sobre todo, a través del libre intercambio de saberes, transformados éstos en productos y servicios.

Ya Mises en su libro La acción humana define a ésta como «una conducta consciente, movilizada voluntad transformada en actuación, que pretende alcanzar precisos fines y objetivos [...]. La acción constituye la esencia del hombre, el medio de proteger su vida y elevarse por encima del nivel de los animales y las plantas». ${ }^{46}$ Y todo ello conformándose (como más tarde afirmaría Kirzner a través de su concepto de función empresarial ${ }^{47}$ o empresarialidad), ${ }^{48}$ en una búsqueda de soluciones creadas dispuestas para ser libremente intercambiadas entre los seres humanos, en su objetivo de alcanzar diversos tipos de mejora. Modo éste que la historia de la humanidad ha demostrado ser el más eficaz y respetuoso para que los individuos alcancen sus metas y, las sociedades sus más altas cotas de desarrollo socioeconómico.

46 Mises, L. von (2009). Capítulo I, pp. 15 y 23

47 Huerta de Soto, J. (2004), capítulo 1, p. 39: «La función empresarial en sentido estricto, consiste básicamente en descubrir y apreciar (prehendo) las oportunidades de alcanzar algún fin o, si se prefiere, de lograr alguna ganancia o beneficio, que se presentan en el entorno, actuando en consecuencia para aprovecharlas».

48 Kirzner, I.M. (1998). Para Kirzner la empresarialidad implica fundamentalmente perspicacia (alertness), actitud ésta referida a estar en un permanente alerta para captar y descubrir oportunidades hasta ese momento no vistas por los demás. (Capítulo II). 
Es por ello, que hablar de educación desde una perspectiva austriaca, implica hablar de una «acción humana» orientada esencialmente al desarrollo del constante aprendizaje, el cual es, ha sido y seguirá siendo la base de todo nuestro progreso como especie y civilización. Es importante precisar aquí, que la información per se por el hecho de ser descubierta no posibilita por si misma mejora alguna, necesita ser diseñada, es decir, transformada en productos o servicios y ello no es posible sin educación previa.

Ante todo ello no parece, por tanto, exagerado aseverar que el binomio empresarialidad-educación adquiere en el ámbito de lo humano un sentido trascendente, ya que en el cómo se organizan las sociedades para educarse, en esa medida su «acción humana» es más o menos enriquecedora individual, social y económicamente para todos sus miembros.

Pasemos por tanto, a analizar algunas propuestas de lo que serían las bases psicopedagógicas de una Educación conformada desde la perspectiva de la Escuela de Economía Austriaca.

\section{Empresarialidad y educación: principios pedagógicos}

Comentábamos anteriormente que en el binomio empresarialidadeducación radica la clave del menor o mayor desarrollo de los humanos como personas y sociedad. Si por empresarialidad entendemos toda acción humana orientada a la consecución de algún tipo de mejora y por educación, todo conocimiento descubierto disponible para ser intercambiado (es decir, convertido en producto o servicio), si queremos que la educación sea eficaz es importante recordar aquí la ligazón que la Escuela Austriaca hace entre empresarialidad y conocimiento. Para la Escuela Austriaca la clave del concepto de empresarialidad radica fundamentalmente en el descubrimiento de un conocimiento que se caracteriza por ser:

— subjetivo de tipo práctico (conocimiento experiencial y no formal);

- privativo de cada persona (según su conocimiento del mundo);

- disperso (diseminado entre todos los individuos); 
- tácito (procesos de conocimiento no articulables por la persona: hábitos, tradiciones, etc.)

- ex nihilo (conocimiento creado de la nada); y

- transmisible (conocimiento generador de aprendizaje, de coordinación y ajuste social).$^{49}$

Por tanto, si en nuestras sociedades queremos alcanzar una auténtica educación liberal deberemos hacer posible a través de ella escenarios socioeconómicos y procesos pedagógicos que desarrollen al máximo dichas características de empresarialidad y conocimiento. Y más cuando sabemos la importancia que tiene la relación existente entre educación y economía.

En este sentido, para que el paradigma austriaco «descubrimiento, desarrollo e intercambio de todo conocimiento» alcance su máxima expresión de mejora, se hace inevitable que sean respetados dos grandes principios liberales:

1. la educación en todo momento debería ser privada y libre, y en la medida de lo posible adecuarse pedagógicamente a las propias capacidades individuales $\mathrm{y}$,

2. de los «saberes» conseguidos con dichas capacidades individuales (y transformados bien en productos, bien en servicios) debería estar siempre garantizado el libre intercambio de los mismos entre todos los individuos.

Es interesante resaltar aquí que es difícil, por no decir imposible, que si se anula lo primero, pueda existir lo segundo. Es decir, allí donde no existe libertad educativa alguna para el desarrollo de las propias capacidades, es prácticamente inexistente la

49 Huerta de Soto, J. (1994, pp. 47 y 48): «Luego el hombre, cada vez que actúa y ejerce la función empresarial, lo hace desde una forma característica, sólo propia de él, es decir, personal e irrepetible, que tiene su origen en intentar lograr unos objetivos o visión del mundo que actúan como incentivo y que, en sus distintas características y circunstancias, sólo él posee. [...] De ahí la importancia que tiene el no desaprovechar la función empresarial de nadie. Incluso las personas más humildes, menos consideradas socialmente, y menos formadas desde el punto de vista articulado, poseerán al menos con carácter exclusivo pequeños trozos o parcelas de conocimiento o información que podrán tener un valor determinante en el curso de los acontecimientos históricos. Desde esta óptica resulta evidente el carácter esencialmente humanista de la concepción de la empresarialidad». 
posterior motivación para el intercambio de los «saberes» adquiridos. En otras palabras, no es posible un mercado libre sin la exitencia previa de una educación libre, ${ }^{50}$ pues los humanos cuando gozamos aprendiendo es lo que más nos estimula a intercambiar lo aprendido.

Por tanto, ante dicho desafío educativo parece fundamental hacerse la siguiente pregunta ¿Desde una perspectiva austriaca, cuáles podrían ser las claves psicopedagógicas que motivando el aprendizaje, motivarían posteriormente el intercambio de saberes? Repasemos a continuación algunos modelos psicopedagógicos que de manera reiterada defendemos los diversos autores austriacos (bien es cierto que hasta el momento de una manera poco sistematizada).

\section{Educación en casa (Homeschooling y/o Unschooling)}

En primer lugar, la Escuela Austriaca (como ya hacían los economistas clásicos), defiende con toda claridad la diferenciación entre Educación y Escolarización, y otorga a los padres, en tanto transmisores de dicha educación, total protagonismo a la hora de decidir la forma y contenidos que crean más convenientes para la educación de sus hijos. Es desde esta perspectiva que los austriacos hacemos una clara apuesta por la defensa del modelo de homeschooling51 («Educación en Casa») y/o unschooling 52 (plena autonomía educativa de los padres para con sus hijos).

50 Está comprobado en los países de nuestro entorno que a mayor Planificación Central de la Educación, paulatinamente es menor el desarrollo del libre mercado. En el caso de España es muy ilustrativo en las periódicas encuestas que se hacen todos los años en las universidades, el alto nivel de universitarios que desean ser funcionarios.

51 Molina, P. (2005). «Su nacimiento ha de interpretarse no sólo como parte del proceso natural de evolución de los sistemas educativos, que también, sino especialmente como un mecanismo de autodefensa al que los padres se ven abocados frente a un modelo estatal en manos de la izquierda, que ha transformado el concepto de educación, basado tradicionalmente en la transmisión de conocimientos y de un determinado legado moral y religioso, en un fiero crisol con el que manipular las conciencias de la futura población adulta según la agenda política marxista».

52 Zaldivar, J.I. El movimiento del unschooling. «El unschooling toma como referencia para la organización del aprendizaje la necesidad de permitir a los niños 
Si tuviéramos que señalar alguna diferencia significativa entre ambos modelos educativos, podríamos decir que, para los defensores del unschooling, el homeschooling se quedaría en un mero «traer el aula al hogar» ${ }^{53}$ (se enseña lo mismo que en el colegio, pero en casa y en un entorno de valores familiares); en tanto que el unschooling ${ }^{54}$ refiere más a un modelo educativo totalmente libre y diseñado por los padres en el mundo real de la vida cotidiana (diríamos que es completamente libertario). Ahora bien, más allá de las disquisiciones de los puristas de ambos conceptos, su denominador común es el total protagonismo de los padres en la educación de sus hijos.

A los austriacos (como a los liberales clásicos), les es difícil creer que el estado conozca y sepa mejor que los propios padres lo que es mejor para los hijos. ${ }^{55}$ De igual modo, también les es difícil creer que las identidades individuales de los hijos desarrolladas por los propios padres sean más débiles que las desarrolladas por un estado de inevitable identidad amorfa, estandarizada y colectivista. ${ }^{56}$

Si bien no es este el momento de profundizar en el desarrollo psicológico ${ }^{57}$ de la identidades personales, sin embargo, si es interesante resaltar, por ejemplo, que en los diversos estudios realizados al respecto de la personalidad de los empresarios, si por

y niñas aprender a través de las experiencias de la vida natural. Dentro de estas experiencias están los juegos, las responsabilidades del hogar, las experiencias de trabajo y la interacción social. En consecuencia, su rechazo a las escuelas es frontal».

53 Mascaró, L. (2011).

54 Martin, D.L. ¿Qué es el Unschooling? Este es un ejemplo de canal youtube de educación libertaria unschooling. DaynaLeighMartin.

55 Burguera M.aA. (2011). En este artículo reciente, la autora resalta la conciencia cívica cada vez mayor de las familias canadienses porque se respeten sus derechos a educar a sus hijos en libertad sin coacción alguna por parte de las instituciones estatales de educación pública.

56 Rallo, J.R. (2005). Interesante artículo de este autor en defensa de la educación privada y la educación en casa.

57 Hayek, F.A. (2011, p. 51): «El problema fundamental que plantean todos los acontecimientos mentales surge pues de la existencia de un orden de cualidades sensoriales más bien que de una reproducción de cualidades existentes fuera de la mente que percibe. En otras palabras, la psicología debe ocuparse de aquellos aspectos de lo que ingenuamente consideramos el mundo externo, que no encuentran lugar en la explicación de ese mundo que nos proporcionan las ciencias físicas». 
algo se caracterizan, es por su fuerte personalidad individual. Personalidades fuertes que les motivan para sacar lo mejor de sus propias capacidades y afrontar los inevitables obstáculos que encuentran en la consecución de sus proyectos. Proyectos que, si bien son de carácter empresarial y económico, a ellos les gusta definirlos más como "proyectos de vida». Tienen claro lo que quieren ser y luchan por conseguirlo a través de las mayores cotas de libertad individual que les permite el entorno. Raro es encontrar empresario alguno que al preguntarle al respecto de lo que es y quiere ser, del origen de su fuerza interior, no aluda a que ésta no haya sido transmitida por los padres. ${ }^{58}$

En este sentido, la familia, como transmisora de valores, como generadora de identidades individuales claras, como contexto de intercambios de todo tipo y a lo largo de toda la vida, difícilmente es superada por institución educativa alguna. ${ }^{59}$

\section{Educación diferenciada}

Pero los economistas austriacos no solamente defendemos como modelo psicopedagógico el modelo de «Educación en casa» ${ }^{60}$ también defendemos claramente el modelo de «Educación Diferenciada» bien sea ésta por razones de sexo, de nivel intelectual, de clase de inteligencia, por razones de edad, o cualquiera otra diferenciación, que partiendo de dichas especificidades, permita a las personas un mayor desarrollo educacional.

58 Nogales Lozano, F. (2008). En este libro hablo profusamente de las características educativas que se desarrollan en las familias empresarias en los ámbitos individual, familiar, social y empresarial; y que son claves para sus éxitos como empresas familiares.

59 Nogales Lozano, F. (2007). En este libro coordinado por mí y escrito por varios autores dedico dos capítulos de gran interés a la temática comentada en este punto. Capítulo 8: «Las culturas familiares: gestión clave para la cohesión y continuidad de las familias empresarias»; y Capítulo 10: «La educación en las familias empresarias». Fundación EOI. Madrid 2007.

60 Rodríguez, J.C. (2010). Interesantes críticas de este autor y miembro del Instituto Juan de Mariana respecto a la oposición radical a la Educación en Casa por parte del actual gobierno español. 
Para el pensamiento austriaco, cada ser humano, si bien es igual en derechos, es único en todo lo demás. Por tanto, cuanto más acerquemos los modelos de enseñanza a las potencialidades específicas de cada ser humano, ${ }^{61}$ mayor será su aprendizaje y motivación para el autodescubrimiento y el posterior intercambio de sus potencialidades con quienes les rodean.

Es en este sentido que la Escuela Austriaca, como defensora de la importancia de los procesos evolutivos del ser humano desarrollados a lo largo de miles de años en todos los campos, entiende, por ejemplo, que los procesos de aprendizaje de hombres y mujeres son innatamente distintos, y que tenerlos en cuenta desde la infancia, es decir, adecuando los procesos de enseñanza a dichas diferencias, es la mejor forma de desarrollar las potencialidades diversas de cada sexo. Harto demostrado está que los cerebros masculinos y femeninos son diferentes ${ }^{62}$ y que, por tanto, tienen procesos de aprendizaje concretos. Cuanto más lo tengamos en cuenta en los diseños educativos, mejor para cada sexo. No se trata de no tener educación mixta, se trata de tener diseños de aprendizaje orientados a las especificidades de cada sexo, ${ }^{63}$ que es distinto. Los resultados de la actual estandarización de la educación están muy claros cuando analizamos sus consecuencias en función del sexo. ${ }^{64}$

Al igual que apostamos por una «Educación Diferenciada» basada en las diferencias sexuales, del mismo modo entendemos que la educación ha de ser diferente en función del «nivel intelectual» de cada alumno. Un alumno con alguna deficiencia mental, un alumno normal, un alumno superdotado, tiene ritmos

61 Rodríguez, J.C. (2006). Interesante artículo de este autor en defensa de las Charter Schools americanas, «escuelas que se sustraen del entramado regulador estatal para seguir otros [modelos pedagógicos] que los directores de los colegios consideran más adecuados», y que desde hace veinte años no dejan de crecer en número dado su éxito escolar.

62 Brizendine, L. (2010).

63 Rodríguez-Borlado, F. (2011).

64 Lacasa, J.M. (2011). Algo falla en los modelos pedagógicos actuales cuando de manera tan clara el fracaso educativo de los niños casi duplica al de las niñas. Ahí están por ejemplo los reiterados informes PISA que año tras año lo confirman. En este sentido, son esclarecedores y contundentes los datos y reflexiones de este autor. 
y modelos de aprendizajes distintos. Lo peor que se les puede hacer es juntarles, pues con los modelos educativos «estándar» todos pierden, se desmotivan (sobre todo los alumnos de nivel intelectual más alto) y en no pocos casos incluso no terminan los estudios básicos. Dichos resultados ni ellos se los merecen, ni la sociedad se los puede permitir sine die.

Pero las capacidades intelectuales de las personas no sólo tienen que ver con el nivel de inteligencia, también con la «clase de inteligencia». No es lo mismo, por ejemplo, una inteligencia «artística» que una inteligencia «matemática». No es lo mismo una inteligencia «lingüística» que una inteligencia «deportiva». No es lo mismo una inteligencia "práctica» que una inteligencia «teórica». ${ }^{65}$ Es decir, los modelos de enseñanza deben de captar y adaptarse no solamente a los «niveles de inteligencia», también a las «clases de inteligencia», pues cuanto más se adapten a dichas diferencias, mayor será la motivación y el aprendizaje de los diversos alumnos. Los psicopedagogos saben que no tener en cuenta las sensibilidades intelectuales de los alumnos (sus «clases de inteligencia»), es una forma segura, no sólo de desmotivarlos prematuramente por el aprendizaje, sino también de desorientarlos más tarde en el mundo laboral, ya que no saben muy bien cómo elegir una actividad con la que se identifiquen y gocen.

Otro tanto podemos decir de una "educación diferenciada» en función de «la edad». Sabemos que no es lo mismo enseñar a un niño, que a un adolescente, a un joven que a un adulto o a personas mayores. Pero en lo que refiere a éstos últimos queda mucho por andar. Con una esperanza de vida a principios de siglo XX cercana a los 65 años, estamos pasando rápidamente a esperanzas de vida cercanas a los cien años en el siglo XXI. Todos sabemos que los adultos si quieren seguir siendo activos en el mundo laboral, y dada la rápida obsolescencia del conocimiento, se están

65 Handy, C. (1996), cap. 12, pp. 214-216. Este autor define nueve formas diferentes de inteligencia, a saber: Inteligencia fáctica, analítica, lingüística, espacial, musical, práctica, física, intuitiva, e interpersonal. En este sentido, para el autor «cada persona es inteligente en alguna de dichas formas, por lo que el primer deber de cualquier escuela sería entonces, descubrir la inteligencia o inteligencias y desarrollarlas». 
viendo obligados a una educación permanente, teniéndose que adaptar además a las nuevas tecnologías. Todos sabemos que la 3. Edad, seguirá formándose cada vez más. Que ello pondrá de manifiesto la caída de muchos mitos al respecto de la incapacidad de las personas mayores para seguir siendo activos y aprendiendo hasta llegar a edades de dependencia. Incluso en esta última edad de la vida también nos llevaremos sorpresas hasta ahora no descubiertas. Por tanto, ante tamaños retos, la «Educación Diferenciada», no solamente es más eficaz, es éticamente más justa que la estandarizada por las instituciones educativas públicas de carácter socializante. ${ }^{66}$

\section{Educación empresarial}

Pero no sólo los austriacos apostamos por la «Educación en casa» y la «Educación Diferenciada» en sus distintas formas, apostamos también por una «Educación empresarial». Una «Educación empresarial» que como concepto va más allá de los estudios de empresariales de las universidades públicas o escuelas de negocios privadas. La «Educación empresarial» que está emergiendo significa para la sociedad el poder conocer y aprender «in situ» a través del mundo de la industria los procesos de generación, transmisión y gestión del conocimiento comerciable. ${ }^{67}$

Así por ejemplo, de los entornos empresariales más competitivos del mundo (laboratorios, grandes corporaciones industriales en los ámbitos de la ingeniería espacial, de las TIC, etc.), están surgiendo las llamadas «universidades corporativas» ${ }^{6} 8$ (bien en solitario, bien en alianzas entre varias). Estas «universidades corporativas» ${ }^{69}$ tienen una gran capacidad para generar conocimiento materializable a mayor ritmo que las universidades

66 Nogales Lozano, F. (2009). Cap. 9: «La Educación en la Postindustrialización».

67 Nogales Lozano, F. (2002).

68 Jarvis, P. (2006).

69 Dos Santos. J.A.B. Tesis Doctoral, La Universidad Corporativa como herramienta estratégica de aprendizaje organizacional. Se puede ver su Introducción en el siguiente blog de Universidades Corporativas: http:/ / unicorporativa.wordpress.com/ 
públicas. Dichas «universidades corporativas» están llamadas a ser la vanguardia del conocimiento práctico, no sólo en los procesos de $\mathrm{I}+\mathrm{D}+\mathrm{i}$, sino en todos los ámbitos del aprendizaje, tanto desde la perspectiva científica, como técnica, laboral y del funcionamiento del mundo de los negocios en los actuales entornos globalizados y de educación virtual. Sus modelos de aprendizaje, indudablemente están revolucionando la educación de unos trabajadores cansados de una educación universitaria alejada del mundo de la realidad empresarial. ${ }^{70}$ Modelos a los que el nuevo liberalismo está empezando a prestar una mayor atención ya que dichos procesos educativos se desarrollan en tres escenarios fundamentales: las empresas, los mercados y la economía, ${ }^{71}$ y todo ello motivando en paralelo en cada persona el uso de sus mejores potencialidades, pues es la forma con la que pueden ser más productivas.

En síntesis, podemos decir que, desde un planteamiento austriaco de la educación, modelos psicopedagógicos como los antedichos, sin lugar a dudas son los que permiten materializar de una manera más eficaz el concepto de «empresarialidad», ya que dichos modelos psicopedagógicos refuerzan más las identidades individuales; se adaptan mejor a las diversas capacidades humanas, estimulan la creación de entornos empresariales potenciadores del desarrollo e intercambio de conocimientos; y todo ello, respetando respectivamente en todo momento, la total libertad de aprendizaje y enseñanza de ciudadanos e instituciones educativas privadas (Figura 5).

${ }^{70}$ Rodríguez-Borlado, F. (2010). El autor aborda en este artículo su crítica al respecto del alejamiento paulatino de la educación pública de la realidad empresarial y por tanto de la defensa de las universidades corporativas como modelo más próximo al mundo del trabajo y a una forma de estudiar más acorde con nuevos medios virtuales. Al respecto dice: «Como era de esperar, estas universidades han suscitado las quejas de quienes entienden que con este modelo se produce la definitiva subordinación de la universidad al mundo empresarial. Pero, por ahora, las tasas de matriculación ascienden cada año — son ya 4 millones de estudiantes en todo el mundoy algunos estiman que en pocos años pueden llegar a superar en número de alumnos a las universidades tradicionales».

${ }^{71}$ ESADE (2010). Este mismo año el 27 y 28 de Septiembre, Gas Natural Fenosa patrocina en Barcelona el «Primer Foro Internacional de Universidades Corporativas» http://www.ejecutivos.es/noticia/13087/Formaci\%C3\%B3n/gas-natural-fenosapatrocina-primer-foro-internacional-universidades-corporativas.html. 
FIGURA 5

EDUCACIÓN Y EMPRESARIALIDAD

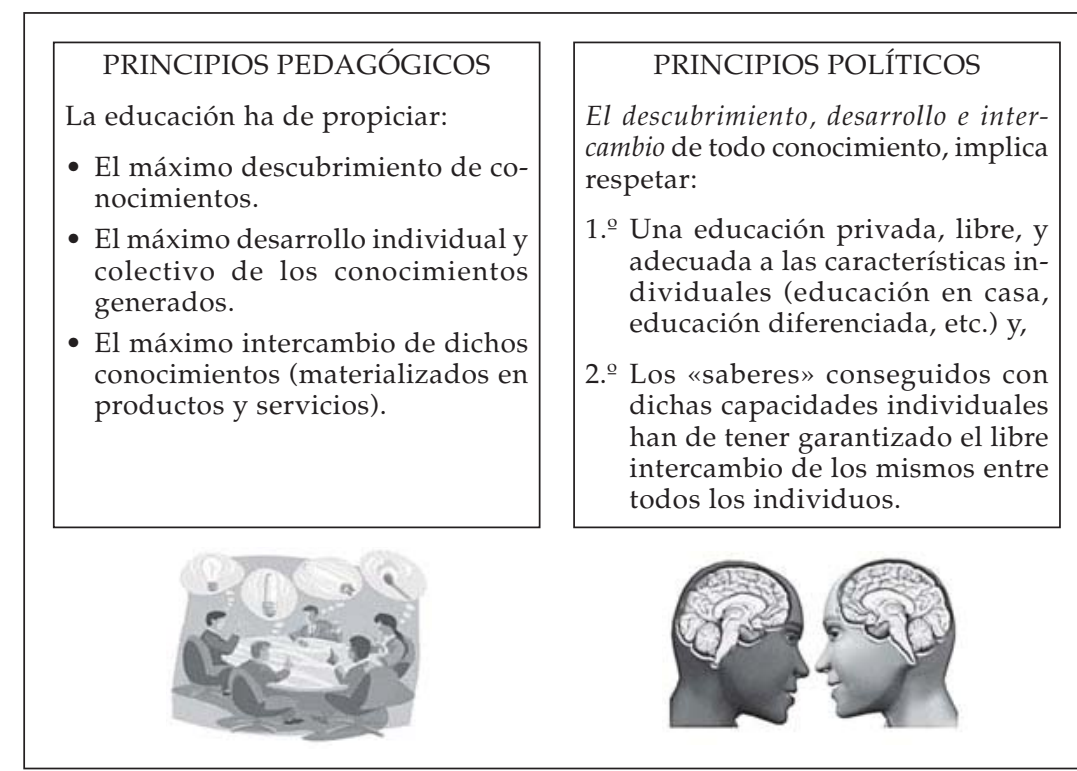

$\mathrm{V}$

\section{SOBRE LOS PRINCIPIOS BÁSICOS PARA UNA EDUCACIÓN \\ DESDE LA PERSPECTIVA AUSTRIACA}

El pensamiento es de suyo lo más libre entre las facultades del hombre; y por lo mismo han tratado algunos gobiernos de esclavizarlo de mil modos; y como ningún medio hay más seguro para conseguirlo que el de apoderarse del origen de donde emana, es decir, de la educación, de aquí sus afanes por dirigirla siempre a su arbitrio, a fin de que los hombres salgan amoldados conforme conviene a sus miras e intereses. Más si esto puede convenir a los gobiernos opresores, no es de manera alguna lo que exige el bien de la humanidad ni los progresos de la civilización. Para alcanzar estos fines 
es fuerza que la educación quede emancipada; en una palabra, es fuerza proclamar la libertad de enseñanza.

ÁNGEL DE SAAVEDRA (Duque de Rivas, 1791-1865)

\section{Bases liberales para una educación desde la perspectiva austriaca}

Podemos concluir que si por algo se caracteriza el liberalismo, es por poner la defensa del individuo y su libertad en el centro de su discurso. Es en dicha defensa de la libertad individual donde nace la existencia de su oposición crítica a toda teoría política de carácter colectivista o estatista que pudiera existir en cualquier ámbito de la vida.

En los apartados anteriores hemos podido ver la importancia que tiene mantener dicha actitud de alerta en el ámbito de la educación. Muy concretamente hemos visto que no es posible el desarrollo de la empresarialidad y del libre intercambio, sin una previa educación libre... y ello significa irremediablemente la institucionalización general de una educación privada, en donde los ciudadanos sean los únicos protagonistas de sus propios diseños educativos. Si en el ámbito educativo el estado ha de tener algún papel, ha de ser solamente el de garantizar que la educación pueda materializarse libremente entre los ciudadanos. Nada más. En otras palabras, sea escolarización privada o pública, la educación siempre ha de ser libre y de gestión privada.

En este sentido y en lo que a las políticas educativas se refiere, si tuviéramos que resumir las ideas liberales básicas (ya existentes desde los primeros economistas clásicos), creo que estaríamos de acuerdo en resaltar como principios originarios los siguientes:

1. El liberal entiende que la defensa de su libertad excluye toda posibilidad de ser «liberado» por organización colectivista alguna. Solo exige una democracia liberal, con todo lo que ello implica. 
2. El respeto a la libertad de educación implica la libre elección del modelo de escolarización por parte de las familias y ciudadanos en general.

3. Para el liberal el «estado» no es un ente abstracto, sino políticos, funcionarios y educadores concretos, los cuales deben ser evaluados por sus resultados, no por sus intenciones.

4. Para el liberal, la educación (como cualquier otra clase de intercambio), ha de funcionar como un mercado en el cual el ciudadano o las familias eligen libremente entre distintas opciones educativas.

Sin lugar a dudas dichos postulados del liberalismo clásico siguen estando vigentes en todo lo que refiere a las políticas liberales educativas. Pero como hemos visto en la presente exposición, creo que desde la perspectiva de la Escuela Austriaca hemos de seguir avanzando, adaptando a los nuevos desafíos dichas políticas liberales.

En este sentido, dado el tamaño de la educación pública y las negativas consecuencias educativas que hemos señalado, para seguir avanzando parece inevitable inspirarse en las dos corrientes internas más importantes de la actual Escuela Austriaca de Economía, a saber:

- el evolucionismo y,

- el libertarianismo.

Estoy firmemente convencido que para alcanzar una verdadera educación en libertad ambas corrientes se complementan.

Sabemos que somos como nos educamos, que la libertad que hoy disfrutamos es el resultado evolutivo de procesos de aprendizaje mayoritariamente de carácter abstracto; que tener en cuenta los aciertos de dicha evolución y transmitirlos de generación en generación es lo que nos ha permitido (sobre todo en los últimos dos siglos), salir victoriosos de las periódicas reingenierías sociales de carácter constructivista impuestas por las teorías nacionalistas y socialistas. Igualmente sabemos también de los efectos perversos de lo que significa la materialización de una Educación Pública centralizada y utilizada como estructura de 
adoctrinamiento ideológico, al margen del deseo de las familias, el respeto al libre pensamiento de los ciudadanos y el libre mercado de enseñanza privada.

Por tanto, si tuviera que resaltar lo que para mí serían unas guías educativas inspiradas en las actuales corrientes de la Escuela Austriaca de Economía, sin ánimo de ser exhaustivo, me decantaría por las siguientes:

1. Desde la perspectiva austriaca las estructuras educativas han de garantizar una educación de libre mercado privado a partir del cual el individuo desarrolle soberanamente su individual identidad psico-socio-económica.

2. Desde la perspectiva austriaca las políticas educativas han de garantizar siempre la libre competencia y diversidad de todos los inversores privados que deseen intervenir en el mercado de la educación.

3. Desde la perspectiva austriaca la elección educativa para el ciudadano y las familias ha de garantizarles siempre la libre:

- Elección de colegio.

- Elección de profesor.

- Elección de fórmula educativa más acorde con sus capacidades y deseos.

- Elección de contenidos educativos respetuosos siempre con la libertad de pensamiento.

4. Desde la perspectiva austriaca las políticas educativas han de garantizar la plena libertad de educación, respetando en todo momento los acuerdos a los que espontáneamente lleguen los interesados en cada caso: familias, alumnos, profesores y colegios.

5. Desde la perspectiva austriaca, el estado ha de tener como única política de educación, garantizar que todo lo anterior sea respetado, de tal manera que en su materialización, ni la estructura ni los contenidos educativos sirvan para transmitir información o adoctrinamiento alguno de carácter constructivista contra, no sólo de la libertad de pensamiento individual, sino y sobre todo, contra la esencia del «pensamiento científico», ese pensamiento reconocido en la «libertad de cátedra» y que es la clave de nuestro constante avance como individuos y civilización (Figura 6). 
FIGURA 6

\section{LA EDUCACIÓN DESDE EL LIBERALISMO AUSTRIACO}

1. Desde la perspectiva austriaca el «estado» no es un ente abstracto, son políticos, funcionarios y educadores concretos, los cuales deben ser evaluados por sus resultados.

2. Desde la perspectiva austriaca las políticas educativas estatales han de garantizar siempre la libre competencia y diversidad de todos los inversores privados que deseen intervenir en le mercado de la educación respetando en todo momento los acuerdos a los que libremente lleguen los interesados: familias, alumnos y colegios.

3. Desde la perspectiva austriaca el respeto a la libertad de educación implica la libre elección del modelo de escolarización: A) Elección de colegio, B) Elección de profesor, C) Elección de contenidos educativos, D) Elección de fórmula educativa.

4. Desde la perspectiva austriaca la educación ha de materializarse como medio a partir del cual el individuo desarrolla su libre pensamiento y por tanto, conforma su identidad psico-socio-económica.

5. Desde la perspectiva austriaca ni la estructura ni los contenidos educativos han de servir como instrumentos de adoctrinamiento, sino como favorecedores del contraste de saberes y desarrollo del «pensamiento científico», clave esencial en nuestro avance como individuos y civilización.

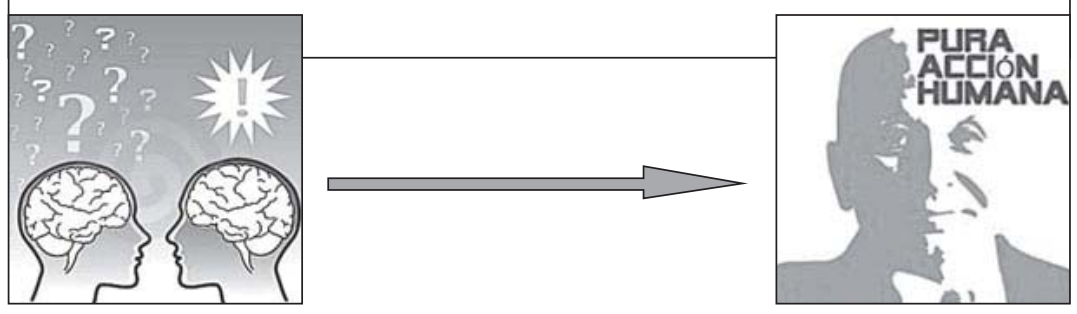

VI

CONCLUSIONES FINALES

Hasta ahora, en occidente ninguno de los apóstoles de la estabilización y la petrificación ha conseguido destruir la innata inclinación del individuo a pensar y a aplicar la razón a todos los problemas. Esto, y sólo esto, pueden afirmar la historia y la filosofía al ocuparse de las doctrinas que pretenden saber exactamente cual será el futuro de la humanidad.

LudWIG VON Mises 
Todo el presente trabajo ha intentado ser un alegato contra la «Planificación Central de la Educación». A lo largo del mismo hemos podido comprobar lo generalizada que está en la mayor parte de los países la Educación Pública y cómo dicho modelo ha ido paulatinamente socavando, no sólo la calidad de la enseñanza sino y sobre todo, el concepto de lo que es una educación en libertad. A partir de dicho concepto hemos visto como sus principales protagonistas, colegios, familias y alumnos, han ido siendo relegados a obedientes transmisores y receptores de una educación diseñada exclusivamente por el estado y dirigida por éste desde una concepción de Planificación Centralizada de la Educación y lo importante que es para desenmascarar y luchar con todo ello, una metodología científica de carácter austriaco (Capítulo 1.ํ).

En el Apartado II, para profundizar en la Educación desde una perspectiva austriaca nos hemos introducido en las que hasta el presente son sus dos principales corrientes teóricas:

1. la teoría evolutiva de las instituciones sociales y,

2. el libertarianismo o anarcocapitalismo.

Con respecto al evolucionismo de concepción austriaca, hemos visto la fundamental importancia que han tenido a lo largo de la historia de la humanidad los libres intercambios de productos y servicios, en definitiva de «saberes», entre las más diversas personas, pueblos y culturas. «Saberes», que se han ido transmitiendo de generación en generación, bien de manera formal o informal, de manera consciente o inconsciente, pero procesos de transmisión de saberes que en definitiva han sido los que han conformado las bases educadoras que más tarde han dado lugar a instituciones sociales tales como el lenguaje, la propiedad, el comercio o las leyes a partir de las cuales se garantizaban dichos intercambios y derechos privados. El denominador común que ha hecho posible todas ellas, sin lugar a dudas ha sido la permanente transmisión de toda la información y conocimiento que cada persona y colectivo iba generando e intercambiando. En este sentido, defendíamos que había que ver la educación como una institución evolutiva básica y esencial para entender la construcción de todas las demás instituciones sociales evolutivas; pues gracias a la 
diversidad de conocimientos y su libertad para ser generados y trasmitidos a lo largo de nuestra historia humana hemos evolucionado y llegado a ser como somos en el presente. De aquí emerge, cuando de educación hablamos, la importancia que tiene el respetar dichos principios evolutivos, evitando en todo momento que la educación sea utilizada como instrumento de reingeniería social por poder alguno.

En esta misma línea, aunque ya desde una perspectiva anarcocapitalista, incidíamos en la importancia de salvaguardar en todo momento la libertad de educación del poder omnipresente del estado. Y afirmábamos que la mejor forma de hacerlo era separando siempre la educación del estado. En este sentido aseverábamos que una concepción libertaria de la educación debía garantizar en todo momento:

1. La total libertad e implantación de los mercados privados de enseñanza.

2. Ausencia de toda coacción totalitaria (en contenido y forma) en toda transmisión educativa.

3. El total protagonismo de proveedores y clientes (escuelas y familias), en el diseño y dirección de las estructuras y contenidos educativos como mejor garantía y eficacia para una educación en libertad.

En el Apartado III al abordar el tema «Educación y socialismo», veíamos con Hayek como la educación tenía que ver con dos fundamentales aspectos de la civilización:

- la transmisión en el tiempo de nuestra acumulación de conocimiento, $y$

- la comunicación y contrastación entre los contemporáneos de información sobre la cual puedan basar su acción (base del pensamiento científico)

denunciando que ambas cuestiones eran inviables de materializar desde una estructura de «educación pública» y dirigida desde un concepto socialista de Planificación Central de la Educación. Pues «la transmisión en el tiempo de nuestra acumulación de 
conocimiento", de facto tiene que ver con el respeto a la civilización heredada y su evolutivo enriquecimiento (cosa imposible para el socialismo dado su objetivo constructivista). En tanto que «la comunicación entre los contemporáneos de información sobre la cual puedan basar su acción», tal conducta pedagógica es imposible en el socialismo, pues como toda ideología racionalista está orientada exclusivamente a imponer sus teorías, no a refutar científicamente conocimiento alguno.

Más aún, denunciábamos que su modelo de «educación pública» sólo era sostenible como consecuencia de distintas y coordinadas formas de coacción socialista realizadas sistemáticamente a lo largo de todos los itinerarios de la enseñanza pública (coacción a las familias, a los alumnos, a los centros privados, a los ciudadanos en general, vía imposiciones como la zonificación, los contenidos curriculares de claro objetivo adoctrinador, la obligatoriedad de las cargas impositivas a toda la ciudadanía al margen de que se eduquen o no en colegios públicos, etc.).

Resumiendo, afirmábamos que era inviable una educación libre en un sistema con «educación pública» y dirección centraliza. Que ante ello la única opción factible era sacar al estado de la educación, dejando que sus protagonistas principales (familias, alumnos y colegios) tuvieran absoluta libertad para conformar sus propios mercados libres de educación privada.

Por su parte, en el Apartado IV entendíamos la empresarialidad como toda acción humana orientada a la consecución de algún tipo de mejora y, por educación, todo conocimiento que posibilitaba diseñar o transformar la información descubierta en un producto o servicio disponible para ser intercambiado. En este sentido decíamos que el binomio empresarialidad-educación adquiere en el ámbito de lo humano un sentido trascendente, ya que en el cómo se organizan las sociedades para educarse, en esa medida su «acción humana» es más o menos enriquecedora individual, social y económicamente para todos sus miembros.

Ello nos llevaba a afirmar que si en nuestras sociedades queríamos desarrollar una auténtica educación liberal, deberíamos a través de ella hacer posible escenarios socioeconómicos y procesos pedagógicos que desarrollasen al máximo ambas características de empresarialidad y conocimiento. En este sentido enfatizábamos 
que una educación liberal orientada a la empresarialidad en esencia debería propiciar:

- el máximo descubrimiento de conocimientos

- el máximo desarrollo individual y colectivo de los mismos y, - el máximo intercambio de dichos conocimientos (materializados en productos y servicios).

Afirmando que para el logro de dichos objetivos de «descubrimiento, desarrollo e intercambio de todo conocimiento» era imprescindible respetar dos grandes principios liberales:

1. La educación en todo momento debería ser privada y libre, y en la medida de lo posible adecuarse pedagógicamente a las propias capacidades individuales (educación en casa, educación diferenciada, etc.) y,

2.. De los «saberes» conseguidos con dichas capacidades individuales (y transformados, bien como productos, bien como servicios) debería estar siempre garantizado el libre intercambio de los mismos entre todos los individuos.

Aseverando que es imposible anular el primero de los principios, si queremos que exista el segundo.

Por último, en el Apartado V, resumíamos lo que a nuestro juicio deberían de ser algunas de las bases para una política educativa respetuosa con los principios del liberalismo clásico y austriaco.

Por tanto, dejamos abierta la hipótesis en el sentido de, si existiese un corpus teórico basado en los principios de la Escuela Austriaca de Economía, servirían de motivador y guía para que los movimientos sociopolíticos liberales pudiesen movilizarse en su objetivo de conseguir un sistema de enseñanza, que basado en el libre mercado garantizase una educación en libertad...; serviría de gran acicate científico para redefinir los principios educativos desde el respeto a la libertad de pensamiento individual; al protagonismo de familias alumnos y colegios en la implantación de una plena libertad de mercados privados de enseñanza; así como también, dotaría en todo momento de mayores garantías de 
respeto a los principios evolutivos que como civilización nos han permitido llegar hasta el presente y por tanto, de ser evitados los riesgos totalitarios de carácter constructivista que pudieran existir, bien en los contenidos educativos o en el uso colectivista de las instituciones educativas por parte de los estados (Figura 7).

FIGURA 7

CONCLUSIONES TEÓRICAS

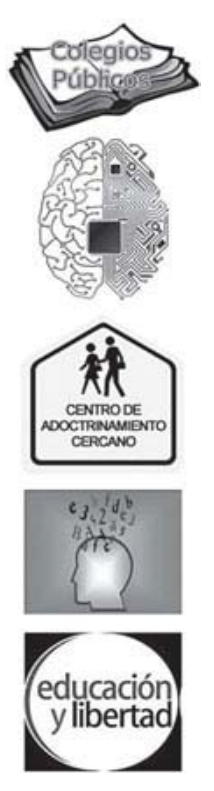

Primero:

La Educación Pública ha empobrecido la calidad, la diversidad y la libertad educativa.

Segundo:

En el evolucionismo y el anarcocapitalismo austriaco existen principios educativos que nos preservan de contenidos e instituciones totalitarias.

Tercero:

La educación libre es imposible en un sistema de «educación pública» socialista de planificación centralizada.

Cuarto:

La educación de la acción humana es la mejor forma de desarrollar las actitudes y aptitudes de empresarialidad existentes en todos los seres humanos.

Quinto:

Dada la actual estandarización de la educación y el riesgo que ello supone para la libertad de pensamiento, se hace necesario redefinir desde la metodología de la Escuela de Economía Austriaca los principios que garantizarían una educación libre.

\section{REFERENCIAS BIBLIOGRÁFICAS}

Brizendine, L. (2010): El Cerebro Femenino. Editorial RBA Libros. Barcelona.

- (2010): El Cerebro Masculino. Editorial RBA Libros. Barcelona.

DiceY, A.V. (1952): Law and Public Opinion in England. 1952.

HANDY, C. (1966): La edad de la paradoja. Dar sentido al futuro. Apóstrofe. Barcelona. 
HAYEK, F.A. (2006): Derecho Legislación y Libertad. Una nueva formulación de los principios liberales de la justicia y de la economía política. Unión Editorial. Madrid.

- (2008): Camino de Servidumbre. Textos y documentos. Unión Editorial. Madrid.

- (2008): Los fundamentos de la Libertad. Unión Editorial. Madrid.

- (1990): La Fatal Arrogancia. Los errores del socialismo. Unión Editorial. Madrid.

- (2011): El orden sensorial. Los fundamentos de la psicología teórica. Unión Editorial. Madrid.

- (2010): «La Fuente de la Hibrys Científica». Procesos de Mercado. Revista Europea de Economía Politica. Volumen VII, n. ${ }^{-}$ 2, otoño 2010, pp. 241 a 258.

Humboldt, W.V. (2009): Los Limites de la Acción del Estado. Editorial Tecnos. Madrid.

Huerta De Soto, J. (2010): Socialismo, Cálculo Económico y Función Empresarial. Unión Editorial. Madrid.

- (1994): Estudios de Economía Política. Unión Editorial. Madrid.

GARrison, R.W. (2001): Tiempo y Dinero. La macroeconomía de la estructura del capital. Unión Editorial. Madrid.

JARvis, P. (2006): Universidades Corporativas: Nuevos modelos de aprendizaje en la sociedad global. Ediciones Narcea S.A. Madrid.

KIRZNER, I.M. (1998): Competencia y Empresarialidad. Unión Editorial. Madrid.

Malthus, T.R. (2010): Primer ensayo sobre la población. Minerva Ediciones. Madrid.

MAsCARó, L. (2010): Educación y Libertad. Una defensa del homeschooling como máxima expresión de la libertad educativa. Editorial Lulu.

- (2011): Enseñar a pescar (Educando en casa). Editorial Lulu.

Menger, C. (1998): Principios de Economía Política. Unión Editorial. Madrid

- (1998): El método de las Ciencias Sociales. Unión Editorial. Madrid.

Meseguer, C.M. (2009): La teoría Evolutiva de las Instituciones. La perspectiva austriaca. Unión Editorial. Madrid. 
Mill, J.S. (2008): Principios de Economía Política. Editorial Síntesis. Madrid.

- (1962): Sobre la Libertad. Fontana. Baleares.

Mises, L. von (2009): El Socialismo. Análisis económico y sociológico. Unión Editorial. Madrid.

- (2009): La Acción Humana. Tratado de economía. Unión Editorial. Madrid.

- (2010): Teoría e Historia. Una interpretación de la evolución social y económica. Unión Editorial. Madrid.

- (2011): La mentalidad anticapitalista. Unión Editorial. Madrid.

Nogales Lozano, F. (2008): La Familia empresaria. Aprenda a diagnosticar sus déficits y potencialidades. Díaz de Santos. Madrid.

- (2007): La Empresa Familiar y los nuevos retos de Gestión. Fundación EOI. Madrid.

- (2002): «La Gestión del conocimiento organizacional y su coaching directivo». Revista Training Development Digest. Mayo. Madrid.

NeILl, A.S. (1986): Summerhill. Editorial Eumo. Barcelona.

SENIOR, N.W. (1836): Outline of the Sciencie of Political Enonomy.

O'DRISCOLL, G.P. Jr. y Rizzo M.J. (2009): La Economía del Tiempo y de la Ignorancia. Unión Editorial. Madrid.

Penalva, J. (2011): Corrupción en la Universidad. El ocaso de la educación. El triunfo de la endogamia. Editorial Ciudadela. Madrid.

RothbARD, M.N. (2009): La Ética de la Libertad. Unión Editorial. Madrid.

- (1999): Historia del Pensamiento Económico. Volumen I: El pensamiento económico hasta Adam Smith. Unión Editorial. Madrid.

- (2006): Historia del Pensamiento Económico. Volumen II: La economía clásica. Unión Editorial. Madrid.

Smith, A. (2004): La teoría de los Sentimientos Morales. Alianza Editorial. Madrid.

- (2011): La riqueza de las naciones: libros I-II-III-IV y V. Alianza Editorial. Madrid.

West, E.G. (1994): La Educación y el Estado. Un estudio de economía política. Unión Editorial. Madrid. 
Zanotti, G. J. (2010): «La Filosofía Política de Ludwig Von Mises». Procesos de Mercado: Revista Europea de Economía Política. Volumen VII, n. 2, otoño, pp. 109 a 145.

\section{Tesis doctorales y trabajos de investigación}

Dos Santos. J.A.B.: Tesis Doctoral, La Universidad Corporativa como herramienta estratégica de aprendizaje organizacional. http: / / unicorporativa.wordpress.com/

Nogales Lozano, F. (2009): La Gestión del Talento Directivo en la sociedad postindustrial. Universidad Pontificia de Salamanca (Campus Madrid).

\section{Artículos en diarios y blogs}

Burguera, M. ${ }^{\mathrm{a}}$ A. (2011): Familias canadienses piden que la escuela respete los derechos educativos de los padres (26 de julio). www.aceprensa.com

DeliBes, A. (2007): La desaparición del pensamiento liberal en la educación. (6 de junio). http:/ /liberalismo.org/

ESADE (2010): Tercer Foro de Universidades Corporativas, organizado por ESADE, Madrid (9 de junio). www.esade.edu

Sotero, P.D. y SuÁrez, E. (2010): El nuevo estudio PISA consagra el estancamiento de la educación española (7 de diciembre). www.elmundo.es

LACASA, J.M. (2011): Cascada de datos (14 de junio). http:/ / blogdelifie.blogspot.com/

Mascaró, L. (2010): Alemania, contra la libertad educativa (19 de marzo). www.juandemariana.org

Molina, P. (2005): Homeschooling (7 de junio). http:/ / liberalismo. org/

RALLO, J.R. (2005): La educación pública o la trampa totalizadora (15 de noviembre). www.libertaddigital.com

- (2005): Por una educación privada y libre (22 de noviembre). www.juandemariana.org

Rodríguez-Borlado, F. (2010): Mi título, ¿para qué? (7 de octubre). www.aceprensa.com 


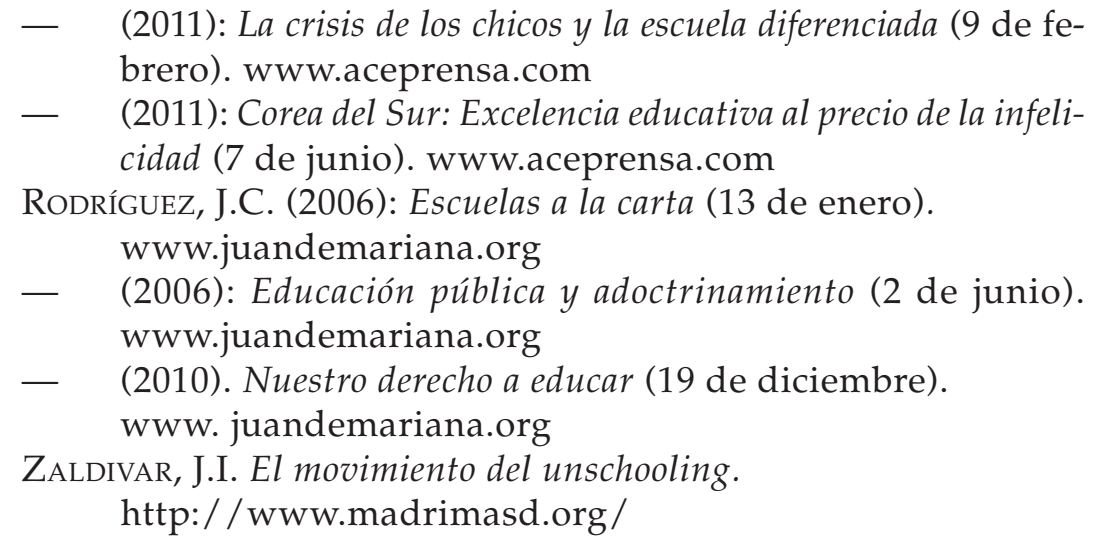

